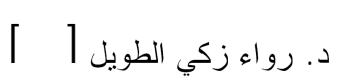

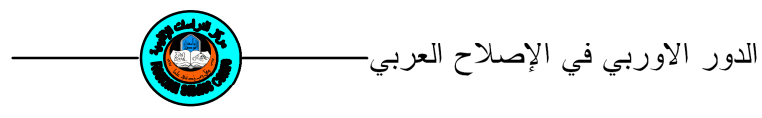

الدور الاوربيفي الإصلاح في الوطن العربي

\author{
دمرواء زكي يونس الطويل \\ استاذ مساعد/ قسم الدر اسات الاقتصادية و الاجتماعية

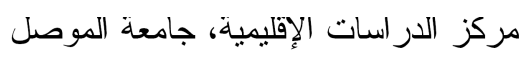

يستحيل تفسير التطورات التي حدثت في العالم العربي والإسلامي باتفصال عن العالم

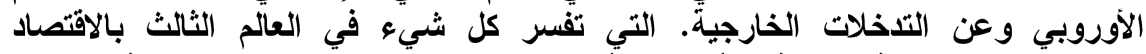

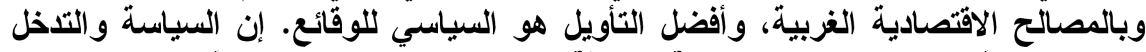

الاستعماري أوجد كيانات الدول العربية الحديثة كالعراق وسوريا ولبنان والئن والأردن وسوالها.

المفدمها

يعرف قاموس اكسفورد الإصلاح "تعديل او تبديل نحو الافضل في

حالة الاشياء ذات النقائص، وخاصة في المؤسسات و الممارسات السياسبة

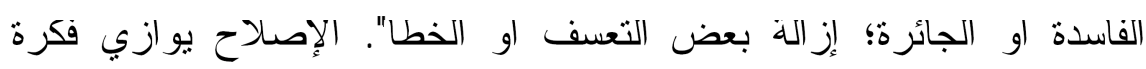

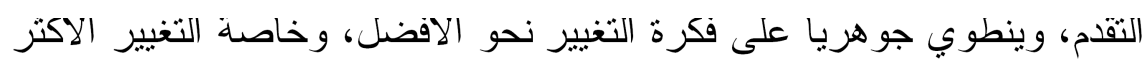
ملائمة من اجل تحقيق الاهداف الموضوعة من قبل اصحاب القرار في حقل معين من حقول النشاط الإنساني(1). يمكن النمبيز بين نالاتة مسنويات للإصلاح الاول: الإصلاح بوصفة استرانيجية للوصول إلى السلطة او

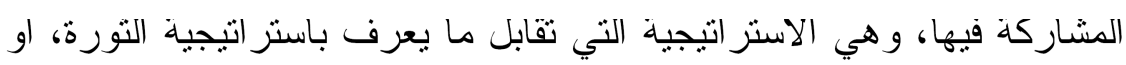


الاتجاه التوري في التغيير، التاني: الإصلاح بوصفة عملية تطوير مجنمعي

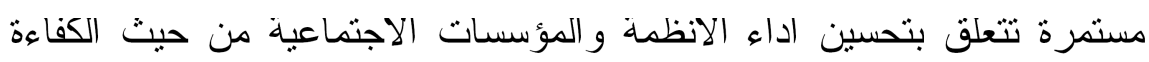
و الفعالية، وهو ما نطلق علبه الإصلاح السياسي او القانوني او المالي او الإداري او الاقتصادي، وغير ذلك، النالث: الإصلاح الفردي، و ابعاده القيمية و الاخلاقية و النفسية و المعرفية و الإدر اكية و السلوكية، وكل ما يتعلق بنقويم النفس وتهذيبها. ان تعريف الاصلاح بختلف تماما عن مفهوم التورة حيث تعد التورة هى مفهوم شَامل للتغير فى شنى قطاعات المجتمع وذلك للاطاحة بنظم الحكم الحاكمة السلطوية باعتبار ها تضر بمصلحة الدولة و ايضا تضمن تعديل الدسنور الحاكم، اما الاصلاح هو تغبر جزئى حبث بشمل احد قطاعات المجتمع فلا يتحقق الابتعاون الحكومات و المجتمع المدنى ومؤسسات القطاع الخاص للسير فى طريق تحقيق ذلك الاصدلاح المنشود(ب).

اهميه البحث: تانى اهمبة البحث فى ان قضبة الاصلاح فى العالم العربى قد اصبحت ضرورة هامة وخاصة مع تطلعات الشعوب ورغبتها فى تحقيق اصلاح حقيقى وتزداد اهمية الموضوع مع انتشار موجه النحول الديمقر اطى ولى على مستوى العالم باكمله وخاصة فى ظل العولمة و انهيار الفو اصل بين الدول المختلفة ومن نم اصبح لا بوجد الفاصل بين ماهو داخلى وما هو خارجى. وتتبع اهمية الموضوع ايضا فى ان البحث يحاول الوصول الى النوايا الخفية

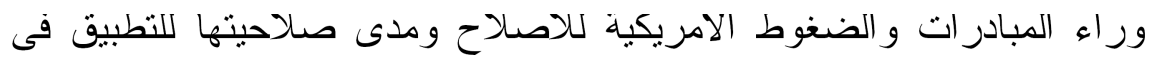

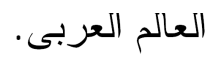




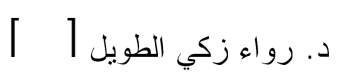

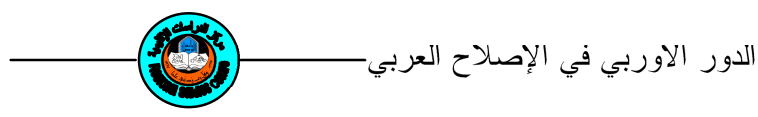

لم تعد افكار التغييز و الاصلاح فى العالم العربى التى ذاعت وتكاترت عقب

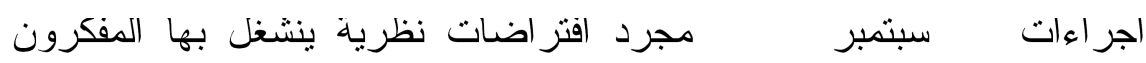

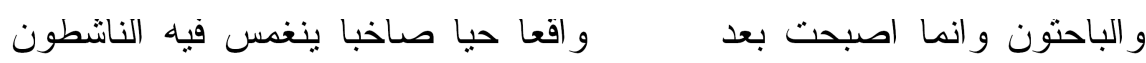
السياسيون و المو اطنون العاديون على امتداد بلاد عربية عديدة.

مشكله البحت: اصبحت قضية الاصلاح فى الوقت الراهن واحدة من اهم

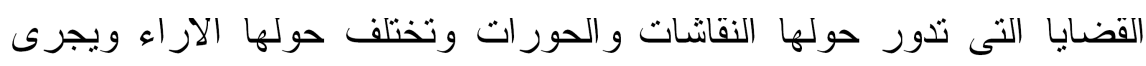

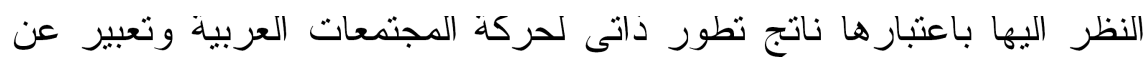

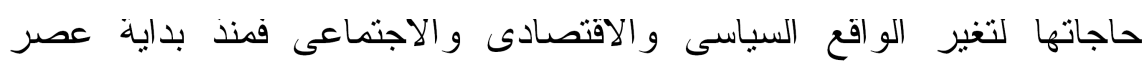

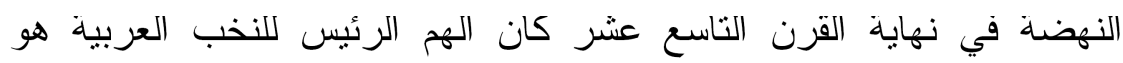

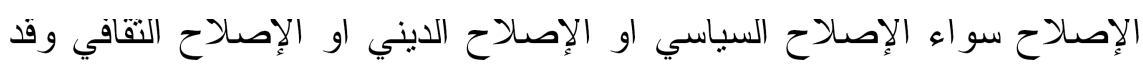

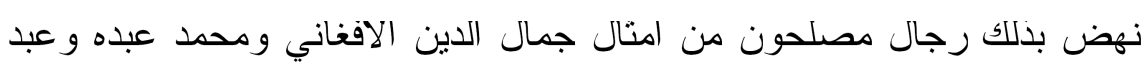
الرحمن الكو اكبي.

و استمرت شعلة الإصلاح يحملها مفكرون مستتيرون من امنال طه

حسين في مصر وجميل صدقي الزهاوي في العراق وعشر ات غير هم في كل

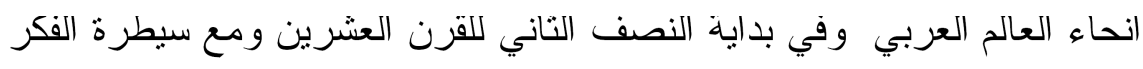

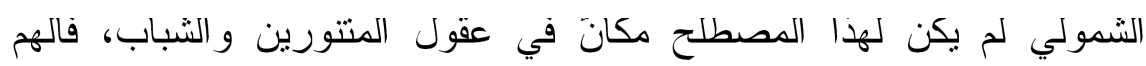

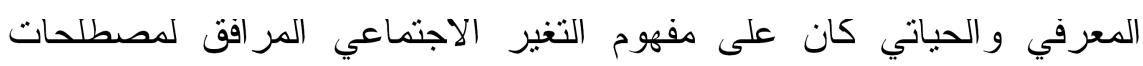
"النورة" و "العنف التوري".

وركزت الدعوات على اولوليات التغير الاقتصادي و الاجنماعي بالطرق الانقابية او التورية مع الدعوة للتحرر الوطني من الاستعمار سياسيا واقتصاديا

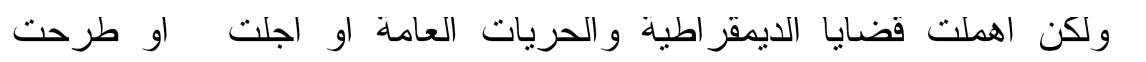

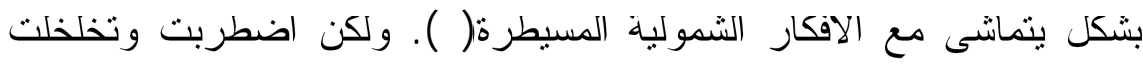


المفاهيم و الافكار لدى المتقفين لعدة عو امل وهي إجهاض التجربة الناصرية التي كانت نمتل المحاولة الجدية الوحيدة بعد محاولة محمد على في القرن التاسع عشر للنهضة الاقتصادية والاجنماعية و السياسية و الخروج من تحت بت بـ سبطرة القوى الكبرى، خضوع الاقطار العربية لانظمة مختلفة منها الملكية

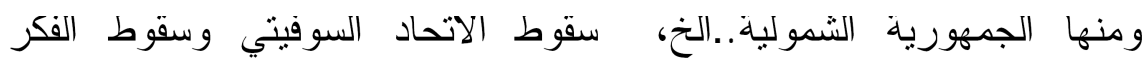
الثمولي معه، انهيار جدار برلين و اثره في العالم و المفاهيم و الافكار ، النظام

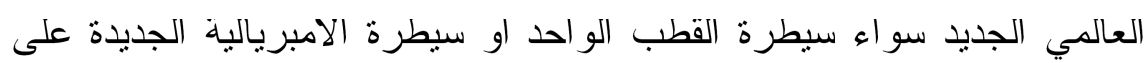

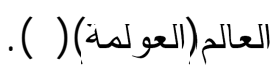
هرضيه البحث: يفترض البحث ان الاصداح في الوطن العربي يجب ان يكون قادر على الاستجابة للو اقع العربي، وتاكبد استقلالية العقل السياسي العربي في حل ومعالجة مشكلات النطور السياسي في المنطقة. هدف البحث: يهدف البحث الى بيان ضرورة الاصداحات و التغيير في الوطن العربي ومناقشنة فكرة رفض التغيير لانه و افد من الخارج، فرياح النغيير ومنذ مدة طويلة تفوق القرنين ناتي من الخارج، وخاصة في العالم العربي وموجات التحديث و الحداتة و التغريب كانت و افدة. و المشكلة هي مضمون هذا التغيير و الثُروط التي تصاحبه و الطريقة التي بفرض بها، فإذا كانت الولايات المتحدة تزى في منجزاتها الني تحققها في العراق اي إعادة بناء الدولة الحديتة وفصل الدين عن الدولة لاحتو اء صيغ التعدد المذهبي و العرقي او مبادرنها للإصلاح و النسوية في السودان او مشروعها للإصلاح فى افغانستان، مبررات لفرض

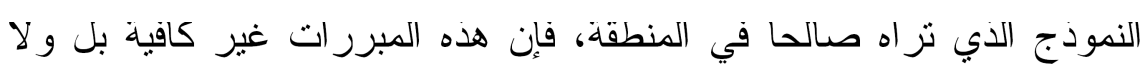
تضمن استقرارا لهذا النموذج لان منطق هذا النموذج هو القوة التي تعوزها المشرو عية الاخلاقية و القانونية. 
في ما يتعلق بمعادلة النغيير و الإصلاح في العالم العربي، فإن هذه المعادلة قد ربطت بين تسوية الصر اع العربي الإسرائيلي والاتجاه قدما نحو الإصلاح، بمعنى ان بدء التغيير و الإصلاح مرتهن بنسوية هذا الصر اع و استرداد الشعب الفلسطيني للحد الادنى من حقوقه المشروعة في الدولة و القدس، بيد ان منطق هذا الربط و الارتهان بسوء نية ام بحسن نبة يبدو انه في الواقع لم ولن يفضي إلى حل وتسوية اي من طرفي هذه المعادلة، فلا النسوية قد تحركت في الاتجاه المنشود وبقيت قضية الإصلاح و التغيير مدونة على جدول الاعمال العربي، ومجرد فكرة لم تر النور بعد رغم العديد من الخطوات هنا وهناك في هدا الاتجاه، ومع ذلك فإن هذه الخطو ات لم ترق إلى مستوى التغيير المنشود عربيا او دوليا واصبحت مقولات الإصلاح و التغييز تزداد كتافة بمرور

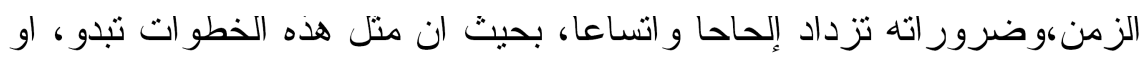

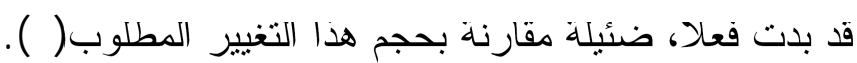
لقد عزز هذه المعادلة الاتفاق الضمني بين الجانب العربي والولايات المتحدة الامريكية، حيث اصبح حل ونسوية الصراع العربي الإسرائيلي مسؤولية الو لايات المتحدة الامريكية، في حين ان العرب و الدول العربية يتكفلون بتتفبذ الثق التاني من المعادلة اي البدء في إجر اءات هيكلية للإصصلاح و التغيير و إرساء قو اعد الديمقر اطية و احتر ام حقوق الإنسان،فالديمقر اطية عملية مؤسسة تقوم على التقاعل المؤسسي و العملية الديمقراطية تتطلب في المقدمة تتمبة قدرات ومؤهلات المؤسسات السياسية لكي تكون قادرة على اداء 
ان الإبقاء على معادلة الإصدلاح و التغيير بشكلها السابق لم يعد يتلاءم و الاوضاع الر اهنة، فمن ناحية خلقت الظروف الدولية و السيطرة الامريكية على شؤون العالم شُروطا ووقائع جديدة في سباق ما بعد ا اسبتمبر والحملة على الإرهاب، ومن ناحية اخرى اصبحت هذه المعادلة فاقدة للمصداقية على الصعبد العربي الداخلي، فالإبقاء على الامر الواقع الر اهن لم ينعكس على ثقدم التسوية للصراع مع إسرائيل، واصبح الربط بين تغبير الاوضاع الداخلية وتسوية الصراع في نظر المو اطنين مجرد حجة لاستمرار الوضع الر اهن، فبعد هزيمة $97 V$ و ضم اسر ائيل لار اضي عربية جديدة، ومااعقب ذلك من نتاز لات سلمت في كثير من الحقوف العربية، انتشرت دعوى بين المتقفين العرب مؤداها ان كل هذا الذي حصل له تفسير واحد، هو غباب الديمقر اطبة وما بيرنب عليه من مصادرة الحرية وحقوق الانسان(V) م: وقد يكون ذلك هو منطق مبادرة الشّرق الاوسط الكبير الامريكية التي قد تحظى بتعاطف اوروبي، و التي ثبرى ساحة الو لابات المتحدة الامريكية من الانحياز لإسر ائيل وتحمل مسؤولياتها إزاء التسوية و السلام في الشرق الاوسط وتبرى اوروبا و الو لايات المتحدة مجتمعتين من تهمة العجز عن الضغط على إسر ائيل لإنجاز السلام و الاستقر ار في المنطقة وهي مبادرة جديرة بالرفض كما فعل الرؤساء و المو اطنون، لانها في سباق المعادلة السابقة تتجاهل طرفا ثالثا مسؤو لا عن إثـاعة عدم الاسثقرار و الإرهاب في المنطقة الا وهو إسر ائيل. وفضلا عن ذلك فهي مرفوضة لانها مفروضة من الخارج بل و لا بعرف حتى المسؤولون حقبقة مضمونها لانها باختصار لم تتاقش معهم ولم تخضع للحوار و التعاون وتقويم مدى قابليتها للو اقع العربي ثقافيا وحضاريا وسياسيا. 
في هذا السباق فإن الاصداحات مطالبة بان تعيد تكييف هذه المعادلة بطريقة

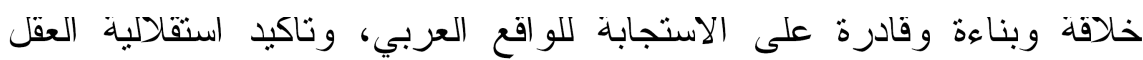
السياسي العربي في حل ومعالجة مشكلات النطور السياسي في المنطقة لذا نما فهم مشترك افضل لدى الباحنين حول دواعي واسباب وشروط الانتقال الى الديمقر اطبة ولم تعد الشروط المسبقة لازمة لحدوث انتقال الى الديمقر اطبة(1). و هذا التعامل الخلاق قد يتاتى عبر إعادة الاعتبار لكل من طرفي هذه المعادلة اي تسوية الصر اع العربي الإسر ائبلي و البدء في الإصلاح و التغيير، اي ان هاتين المعضلنين تحظيان بذات الاولوية في جدول الاعمال العربي وتتر اققان زمنيا اي لا تتقدم إحداهما على الاخرى، و إذا ما تقدمت فينبغي الا يكون ذلك على حساب الثانية، اي باختصار تؤكد الاصلاحات قدرتها على إحداث قطيعة بمعنى ما من المعاني، مع خبرة الماضي المنز اكمة و الجامدة الني افضت إلى الموقف الراهن وذلك لا بعني بالضرورة تقليص مكانة القضبة معنية الفلسطينية وتسوية الصر اع العربي الإسر ائبلي بل بعني بلورة صباغة نظرية ومنهجية مضمونها ان الإصلاح و التغيير ينبغي ان يعزز ويدعم تصدَّ القضية الفلسطينية والنسوية جدول الاعمال العربي، وان تخلق ديناميكية التغيير و الإصلاح شروطا إقليمية وعربية ودولية تفضي في نهاية التحليل إلى تعزيز قدرة العرب الجماعية الديبلوماسية والتقاوضية على تمرير الحل الممكن وباقل الخسائر الممكنة في السياق الحالي، من هنا كان لابد من تحويل جهاز الدولة النقلبدي تحت ضغوط القوى الاوربية الراسمالية فكان ماسمي بالاصلاحات

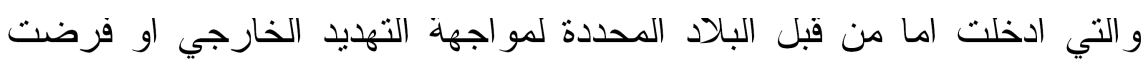
فرضا من دول اجنبية(9). 
و لاششك ان إعادة تاسيس هذه المعادلة على هذا النحو تبدو اكتر جدة وجدية

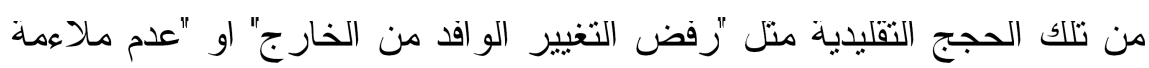
النوقيت"، ذلك ان الو لايات المتحدة اول من بعرف حقبقة هذه الحجج ووظيفتها في الماضي و الحاضر، فهي تعرف ان جوهر هذه الحجج هو الإبطاء و الإرجاء

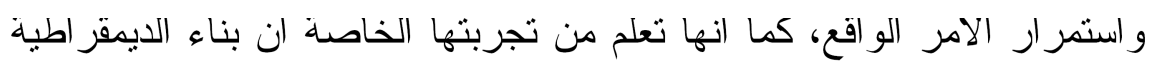
هو عملية داخلية سياسية طويلة تنسكل تاريخبا وليس وفق جدول زمن زمني مفروض من الخارج. بل تعلم الولايات المتحدة الامريكية اكثر من ذلك، فوفقا لدراسة اعدتها مؤسسة كارنجي لابحاث السلام فإن من بين النظم النماني عشرة التي تغيرت على وقع القوة العسكرية الامريكية منذ الحرب العالمبة التانية، خمسة منها فقط هي الني انجزت ديمقر اطية بعتد بها ومنماسكة نسبيا الا وهي المانبا و إيطاليا و اليابان، و الني توفرت فيها شروط مفتقدة في كثير من دول العالم التي ثريد

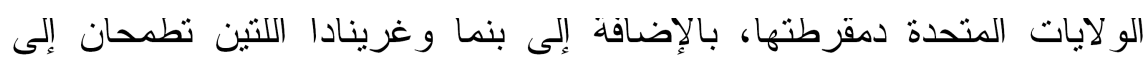

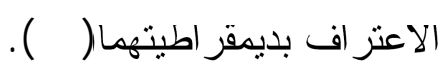

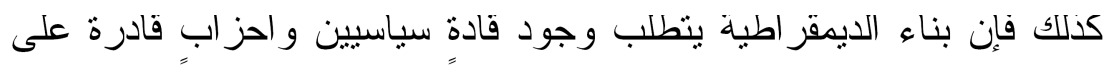
المنافسة بحرية وانتخاباتٍ مفتوحة وحرة. كما بتطلب فصلا بين السلطات، ومستوى اقل من الفساد وحماية للاقليات وحرية النتظيم و الاجتماع و التعبير وصحافة حرة وهي عمليات بطبيعتها لا تتم بين عثبة وضحاها بل بحاجة للانخر اط في عملية تغيير ممندة ومعالجة لمضاعفاتها الو اقعية. و هذه الشروط السابقة عندما تكون مفتقدة فإن المطالبة بالديمقر اطية من فبل القوى الكبرى وخاصة الولايات المتحدة الامريكية ستتخذ طابعا انتخابيا داخليا بل وستخفض سقف الديمقر اطبة حتى بتو اعم مع المنافسة الانتخابية( (1). 
مفهوم الإصلاح الشامل الذي ينشده التيار الإسلامي، يذور حول معنى

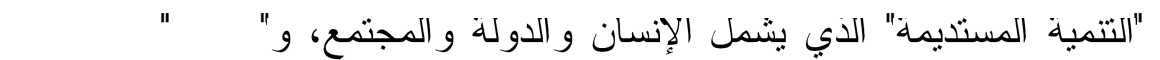
نو احي الحباة السياسية و الاقتصادية و التقافية و المجتمعية التي يشكل فيها الإنسان مركز الدائرة وتلتف حوله دوائر كتيرة، اهمها: دائرة الحرية التي بغيابها تحل بالبشر اعظم كارثة، وتتجسد في حياتهم اعلى صورة من صور الفساد في الارض؛ ذلك ان الله -سبحانه وتعالى - خلق الإنسان، ومنحه حرية المشيئة، و عندما تصادر هذه القيمة الإنسانية العظيمة فإنما تتم المصادرة على معنى وجود الإنسان من الاساس، وتلك ابشع جريمة ترنكب على وجه الارض، باعتبار ان رسالة جميع الرسل و الانبياء تهدف في الاساس إلى تحرير الإنسان من العبودية لغير خالقه سبحانه وتعالى. وقد حسم الإسـام هذا الموضوع بان حمل الإنسان(مشيئة الإرادة الحرة) قل

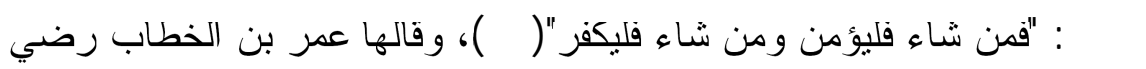
اللّه عنه: "منى استعبدنم الناس وقد ولدتهم امهاتهم احرارَا؟؟"، وراى ان هناك بعض الحقائق حول الحرية ينبغي الإحاطة بها، ليس هناك حرية بدون قدرة، فالذي يقول إنه حر لا بد ان يملك مقومات الرفض كما يملك مقومات القبول، لبس هناك مجال للحرية بالمعنى المطلق، فلا بد ان تتنظم تلك الحرية مع قيم المجتمع ومبادئه و اعر افه، الحرية حق لمن يعمل وينتج ويشارك الاخرين الحياة، المساواة بين الناس اجمعين في ممارسة الحقوق(بار). اما صور

$$
\text { الإصداح الشامل من المنظور الإسلامي فهي : }
$$

ا- الإصلاح التعليمي: الذي يقوم على الطريقة العلمية في اتصال التربية و التعليم بمقتضيات الحاضر و المستقبل تعليميّا لا تلقينيّا، بتصل باحتباجات 
المجتمع، ويشمل كل الامة- ذكورَا و إناتا - ويتحول إلى عمل يومي مستمر ، لا ينتهي بالنخرج من فصول الدراسة، بل يستمر لتاهيل النشه لإخر اج طاقاتهم وقدر اتهم الكامنة، وتزوديهم بكل ما من شانه ان بغرس فيهم القدرة على رجاحة الحكم، و الإعلاء من قيمة الحوار ، ونتبيت معنى الاختلاف و التعدد على انه من

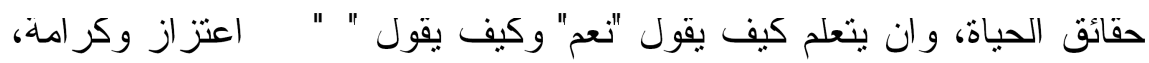
و وان بتعود على التفكير الإبداعي المتمر الذي برفض التقليد، ويتاكد لديه

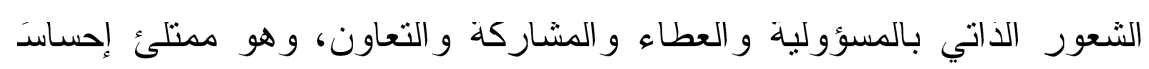

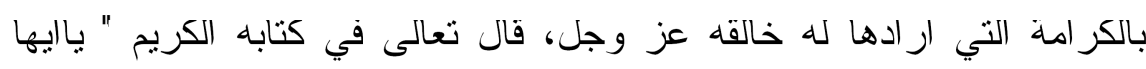
الناس انقوا ربكم الذي خلقكم من نفس واحدة وخلق منها زوجها وبث منها رجالا كثير ا ونساءا و اتقو ا الله الذي تساعلون به الارحام"(ع ا) . ب -الإصلاح الاقتصادي: الذي يتجه نحو العدل الكامل في نوزيع التزوة و الدخول باتباع سياسات عملية صحيحة لبناء نهضة شاملة، تكون الركيزة الاساسية فيها تتمية القدرات، وتهيئة مناخ النشغيل الكامل، وتوفير فرص عمل بله جيدة، وتامين اجنماعي فحَال، وقد اتبتت كتير من تجارب الإصداح الاقتصادي الحديثة -خاصة في التجارب الاسيوية- ان المشروعات الصغيرة من اهم ادوات نوفير فرص العمل،وقد انطلق الاسلام في نظرته للمساو اة من ان اسلم هو العلاقة الاصيلة بين الناس، وعلى هذا الاساس بين الاسلام سباسته الاصلاحية فيما بين المسلمين بعضهم مع بعض وفيما بينهم وبين غيرهم من مو اضيهم او من الامم المختلفة(10)، كل هذا بنطلب قيام روح اجنماعية جديدة بعنة تتعاون فيها حكومة نشطة ذات قدرات فعالة مع قطاع خاص و اهلي يتمتع بالحيوية و الإحساس الو افر بالمسئولية الاجتماعية ومؤسسات مدنية قوية تمتل مختلف فئات الشعب من برلمان ونقابات وصحافة وجمعيات اهلية واجهزة 


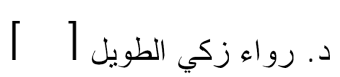

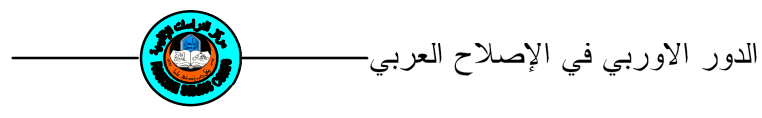

رقابة شعبية، و إصلاح الجهاز الإداري إصلاحًا كاملا وتحديثه وتطويره على مانى ارفع مستوى من مستويات الاداء الإداري الفعال، واعتقد ان مجتمعاتتا تملك إنك من الطاقات و القدر ات في علم الإدارة ما يكفل تحقيق كل ذلك على نحو صحيح تمامًا فالى جانب المساواة فقد كانت مبادئ العدل و القسط و الانصاف من الن المبادئ الجوهرية الني اكدها الاسلام، وجاءت بها ابات القران الكريم وان الله بامر بالعدل و الاحسان(1 (1). ج - الإصلاح السياسي: لبس للتيار الإسلامي اي تصور لنتفيذ الإصلاح السياسي صندوق الانتخاب، وليس من وسيلة اخرى على الإطلاق لتحقيق هذا

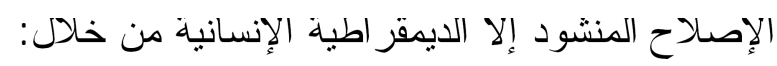
اولا ·- المواطنة في الدولة المدنية المنشودة هي اساس الوجود في المجتمع داخل إطار ديمقر اطي، وكل من رضي بهذا الإطار يكون على قدم المساو اة مع الاخرين بكل اتجاهاتهم الفكرية و السياسية، و الجماهير هي الحكم من خلال انتخابات حرة ونزيهة، مع الناكيد على وضع كل الضمانات التي تحفظ التحييد و النزاهة، حتى يتحول شرف الصوت الانتخابي للفرد إلى جزء لا يتجز ا من شُفه الثخصي، وذلك بفضل مايحمله الاسلام من منظور انساني للوحدة

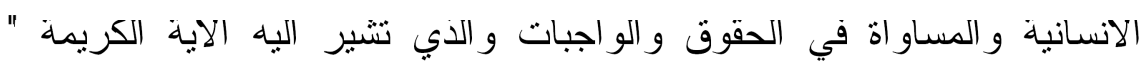
ياابها الناس إنا خلقناكم من ذكر و انتى وجعلناكم شعوبا وقبائل لتعارفوا ان ان

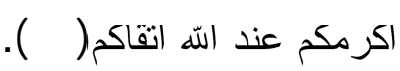
تانبا -النظام الديمقر اطي النبابي -من برلمان واحز اب وتعددية كاملة- هو اكتر الصيغ فعالية لحماية الحرية، والحفاظ على قوة المجتمع، ومنع الاستئنار بالسلطة الذي يكاد يكون عيبًا إنسانيّا لا بخلو منه بشر؛ لذا فإنه يتحتم على نحو 
صارم وضع القو انين و الدساتير و ادو ات المر اقبة و المساءلة التي تحدَ من الاتار

$$
\text { البشعة لهذا العيب على الشعوب و الاوطان. }
$$

تالتا - - إعلاء شان الامة على شان الدولة، فالدولة الديناصور ـكما وصفها

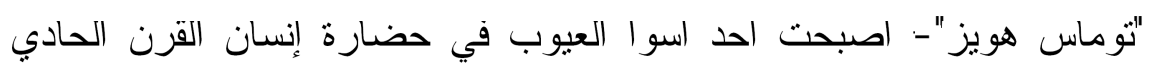
و العشرين؛ الامر الذي يستوجب تقوية الاحز اب و النقابات و الجمعيات الاهلية،

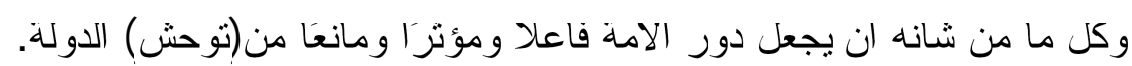
رابعا - - المساو اة السياسية والقانونبة الكاملة بين كل فئات المجتمع وطو ائفه، ووضع كل الضمانات لحماية هذه المساو اة من اي انحر اف سياسي او مدهبي،لان العدل نظام الله وشرعه و الناس عباده وخلقه يستوون ابيضهم هنه و اسودهم، وذكر هم و انتاهم مسلمهج و غير مسلمهم،اما عدله وحكمته(1)

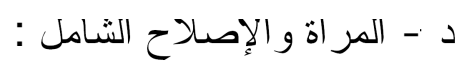
ان الاصل في التكاليف الإسلامية هو العموم، فليس هناك إسلام للاجل و إسلام

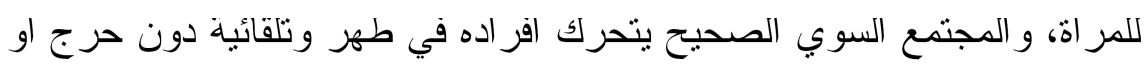
عقد او نوتز في اتصال افر اده بعضهم ببعض .قال تعالى في كتابه الكريم "

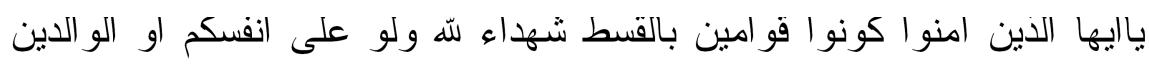
و الاقربين "(9) (1).

كما ان المر اة تكوين عقلي وروحي، ونفسي وجسدي، و الإسلام يحضها

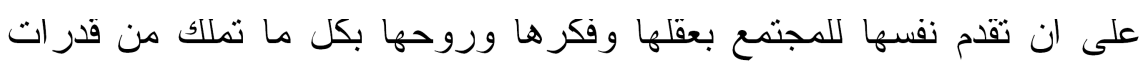
و إمكانات، اما جسدها فلا يهم المجتمع في شيء وليس مطروحًا للاهنمام، و لا يجب ان يكون كذلك، وهذه احد الوجوه الارنقاء بالمراة و الإعلاء من شنانها

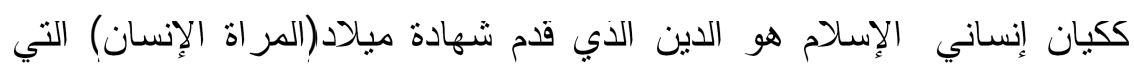

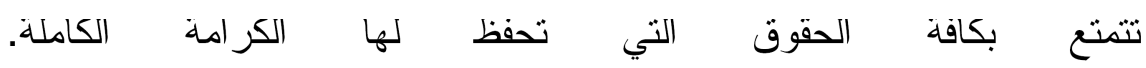


د. رواء زكي الطويل[T]

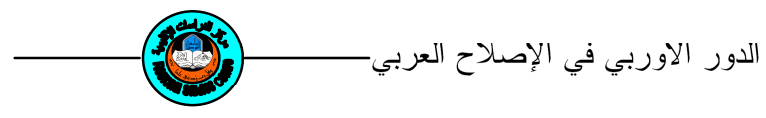

حجاب المر اة المسلمة هو في حقبقته هوية و انتماء قبل ان يكون شكلا و غطاء، وهناك عدة نقاط متقرقة من المهم للغاية طرحها: نقاط هامة ( r): او لا: الخطاب الإصلاحي الإسلامي خطاب بشري، وليس خطابا مقدا؛ و إنما هو اجتهاد بشري في فهم نصوص الإسلام الوطنية، مهما كانت مساحة الاختلاف.

تانبا: ميدان(صناعة الإنسان) وصياغته الصباغة الربانبة السليمة هو اهم ميدان في الحركة نحو الإصلاح. تالتا: هدف الحكم في رؤية النتار الإسلامي هو سعادة المحكومين، وتحقيق السلام و الاسنقرار في الداخل، و العزة و الاحترام في الخارج، و الحاكم وكيل الامة، وليس له عليها سيادة، بل هي سيدنه، وهو خادمها.حيث ياتي مبدا الشورى، والامر بالمعروف و النهي عن المنكر ليؤكد، الى جانب المساواة بين الناس في الحقوق و الو اجبات، و الحكم بالعدل و القسط و الانصاف فضلا عن التكامل الاجتماعي بين جميع المسلمين بااعتبار هم اخوة( (Y). رابعا: الحضارة الإنسانية في رؤية الإسلاميين يجب ان تسير في حماية امرين اساسيين: السيلسة السليمة، و الاخلاق القويمة. السياسة السليمة التي تقوم على لقيل الحرية و العدل و المساو اة بين البثر، فكلهم لادم، و ادم من نراب كما قال

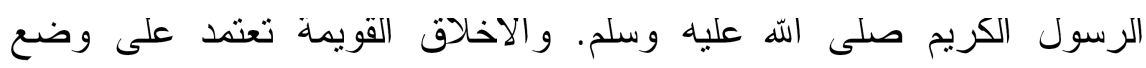
حاجات الإنسان على اساس سليم، وتهذيب اختبار اته ورغباته، وعدم الإلحاح عليه بالالة الإعلانيا الساحقة؛ كي بستبد به حمىلالفتتاء والاستهلاك الدي لا يتوقف عند حد، ويدفع به إلى ما لا تحمد عليه عقباه. المشكلة الامريكية لاى المسلمين هي في التاييد المطلق لاسرائيل في فلسطين، بحيث تداخلت صورة امريكا واسرائيل في مواقع الرؤية العربية 
و الإسـامية، وزاد على ذلك احتلال للعر اف الذي يخالف كل الثُرائع والقو انين و الاعر اف الدولية، وما صاحب ذلك من اقو ال عن حروب دينية نخلو من ابي فهم حضاري محترم لما استقر عليه الناريخ من ارثقاء بالندافع الإنساني المتمر ، نحو إقامة حضارة إنسانية مزدهرة بالعطاء و الحب و التعاون. ان ما يسمى لهى بالإزراب في القاموس الامريكي ليس دقيقا بما يمتله معنى الإزهاب، بل للاسف هو ما بمنل كل خط سياسي يصطدم بالسياسة الامريكية والصهيونية، فهو الصهي مسالة سياسية في حركة السياسة الامريكية اكتر مما هو حركة عنف ضد الامريكيين كتُعب و افر اد.

\section{رض الكيفيه التي يطرح بها التغيير}

ان ما هو مرفوض ليس التغيير في مضمونه المقترح من الخارج بل الكيفية الني يطرح بها نفسه و الطريقة التي يمكن ان ينفذ بها و الثروط الني تصاحب إقراره. فالنعاون و التقاهم و النشاور حول مضمون النغيير هو المدخل الحقبقي إلى تتفيذه وليس القوة و القسر و الإكر اه. من الكتاب العرب الذين وضعو ا مسالة اعادة تتظيم السلطة في دعو اهم الاصلاحية منذ القرن الماضي، لم يكونوا بنطلقون، كما هو في الشان الاوربي الذين تامرو ا بافكار هم، من مجتمع تحولت اوضاعه بفعل تطور قو اه الخاصة، فاقتضى الوضع تحويل مؤسساته السيلسية، اي اعادة ضبط العلاقة بين المجتمع المدني و الدولة، و انما التحويل الذي بدات تخضع له الاقطار العربية جاء اساسا، من التذخل الخارجي وادخال البلاد العربية في الاقتصاد الر اسمالي العالمي(rY)، اما في ما بتعلق بتاكيد الاستقلالبية العربية عبر الرفض فهو بحاجة إلى إعادة نظر إيضا، خاصة حول حدود

$$
\text { الاستقلالبة في الوقت الر اهن(سب). }
$$




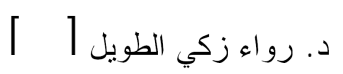

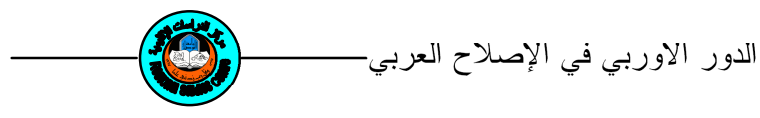

فقد عصف عصر العولمة بعديد من مقومات السبادة والاستقلال وخلق

حالة تداخل كونية في الامن و المصالح السياسية والاستر اتيجية، و لابد ان نعي حدود الاستقلالبة في الوقت الراهن وطبيعتها في اللحظة الحالية وما إدا كان مجرد الرفض هو تاكيد هذه الاستقلالية ام ان الرفض لبس كافيا بل لابد وان البان

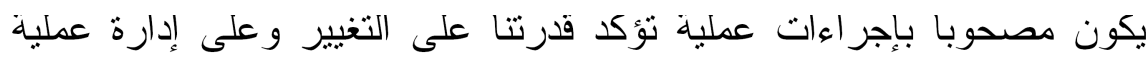
الدمقرطة و الحدانة وقد يكون تزدي اداء النظام السياسي من مجال الامن التاني و التتمية متلا ومن نم الوصول الى مازق سياسي stalemate سبيا للانتقال

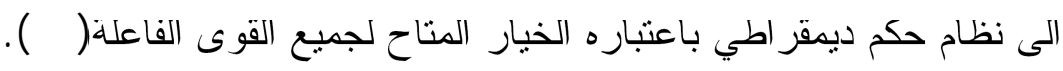

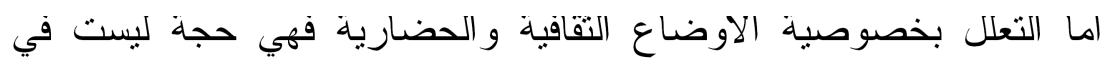
صالحنا إجمالا. تعني هذه الخصوصية الإبقاء على تردي اوضاعنا السياسية

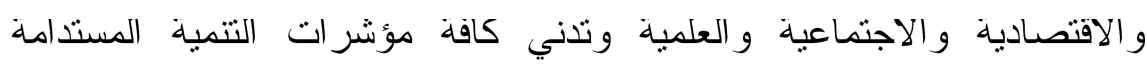

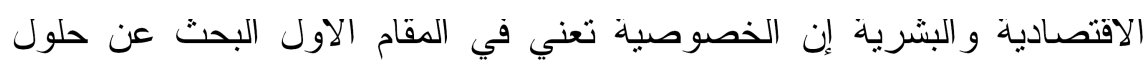

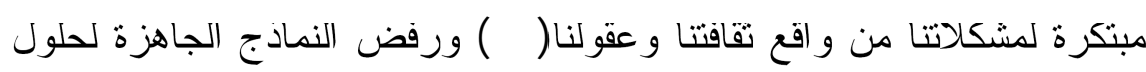
هذه المشكلات الني تولدت في بيئات تقافية اخرى لانها لا نلائم و اقعنا ولكنها

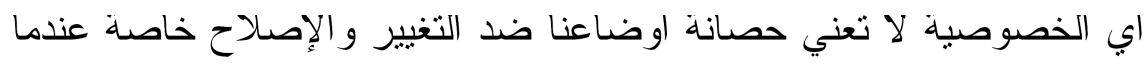

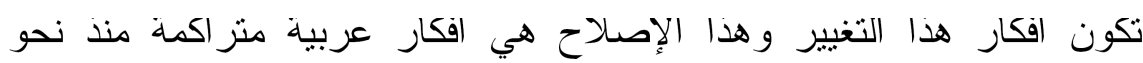
قرنين. - مان.

في ما يتعلق بالحجة القائلة باننا نعرف طريقنا إلى الإصلاح بافضل

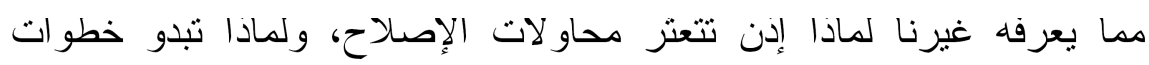

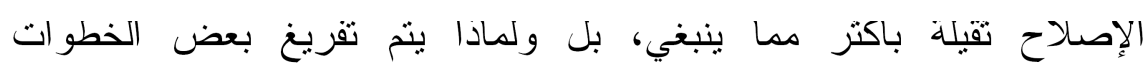

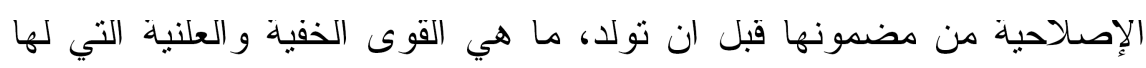

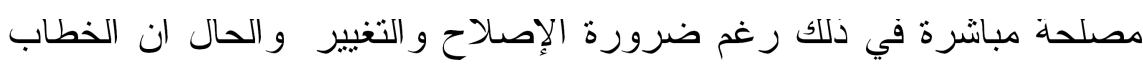


العربي الرسمي حول التغيير هو خطاب تبريرى، ينطوي صر احة وضمنا على

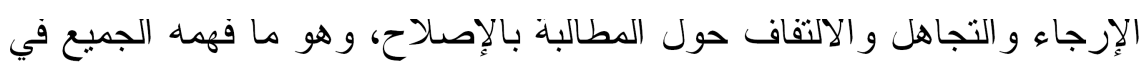
الداخل و الخارج. وذلك يقتضي خطابا جديدا حدينا حول الإصدلاح و التغيير يقطع الصلة بالممارسات الخطابية و البلاغية العربية، خطاب يتميز بالاصالة و الجدة و الجدية و الصدق في التعامل مع مطلب الإصلاح كضرورة عربية وقومبة وقطرية في ن واحد، ودلك يقتضى الاعتر اف الصريح بالحاجة إلى وهى وهي الإصلاح وصياغة اجندة واضحة لمسالك هذا الإصلاح ودروبه السياسية و القانونية و الاقتصادية وبلورة جدول زمني للتنفيذ يكتسب المصداقية الداخلية و الدولية اخذا في الاعتبار الظروف و الملائمات السياسية و الحاجات و العقبات

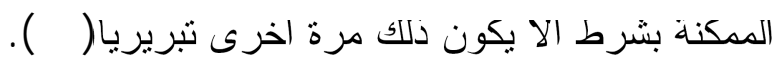
وهذه المبادرة الامريكية كما تعفي اسرائيل من المسؤولية عن تدهور الاوضاع في المنطقة فهي ايضا نستنتها من جدول الاصلاح وتبقي عليها كما هي كما لو كانت تمنل النمودج الكامل غير المنقوص. وفوق ذلك فإن المشروع لا يذكر القضية الفلسطينية لا من قريب و لا من بعيد ويدفع بهذه القضية الى مجاهل النسبان ويبرَئ القوى الكبرى وخاصة الو لايات المتحدة من شبهة التقصبر في مو اجهة استحقاقات التسوية والانحباز المطلق لاسر ائيل وينظر الى ولى الجدار العنصري الذي تقيمه اسرائيل بهدف ضم اكبر مساحة ممكنة من ار اضي الفلسطينيين كما لو كان امر ا مشرو عا.

إذا كان صحيحا ان إنجاز تسوية للصراع العربي الاسر ائبلي قد لا يفتح الابواب كلبة امام رياح التغيير في الشرق الاوسط، فإنه من المؤكد ان تجاهل النسوية سيجعل من الإصلاح مشكلة اخرى بدلا من ان بكون حلا لمشكلات 


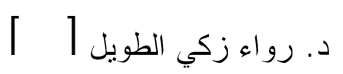

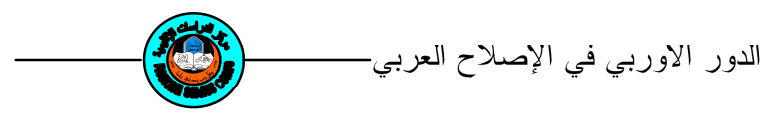

قائمة، يضاف الى ذلك امر ان يتعلقان بهذه الخلفية المضمرة التي تكمن وراء مشروع الثرق الاوسط الكبير ويضعان علامات استقهام كبرى حوله(TV). اولا ان المشروع في ما يبدو يرتبط الى حد كبير باخطاء السياسة الخارجية الامريكية(r/) و الادعاء بتغيير العالم و اقليم الشرق الاوسط الكبير الذي يمند من المغرب غربا حتى باكستان و افغانستان شرقا. تانيا فهو ناكيد الدور الوظيفي للثرق الاوسط في إطار العولمة، اي تامين مسار ات العولمة السياسية والاقتصادية و النقافية عبر تغيير النظم السباسية و ارساء الديمقر اطبة، و هيكلة الاقتصادات وتغيير القيم التقافية التي تمثل مصادر وهير مقاومة محتملة لمشروع العولمة الامريكي باعتباره مشروعا كونبا لا راد له(Y). و لا شك ان هذه المنطلقات الظاهرة و المضمرة لمبادرات الاصلاح الامريكية او الامريكية الاوروبية من شان اظهارها وتحليلها نعبين الطريق الذي ينبني ان يسلكه العرب و ابتكار نمودج التغيير الخاص بهم والذي يعبر عن امانيه وتطلعاتهم، خاصة وان الخطاب الامريكي حول الديمقر اطبة في العالم الاسلامي و العربي و العالم عامة، يفتقد الى المصداقية، ذلك ان التجليات العملية للسياسة الخارجية الامريكية قد حفلت بتتاقضات ظاهرة ومضمرة فهي الني وقفت وساندت اكتر الديكتانوريات العسكرية في امريكا اللاتينبة وحشبة و استبدادا، كما انها ساهمت عن طريق مخابر اتها و اجهزتها المختلفة في اسقاط العديد من النظم و الرؤساء المنتخبين ديمقر اطبا، وكان المعيار الامريكي للتنخل هنا وهناك هو المصلحة الامريكية و الولاء للولايات المتحدة وليس مصالح

$$
\text { شعوب هذه الدول( • (ر). }
$$

و الوعي العربي يخترن في ذاكرته ذلك الرصيد الامريكي فالثعوب لا

تتسى ولكنها قد تغفر للذين اخطاو ا في حقها، ذلك لا يقلل من الضرورة الحبوية 
لاستيعاب الخبرة التاريخية خاصة خبرة الامبر اطورية العتمانية في مواجهة

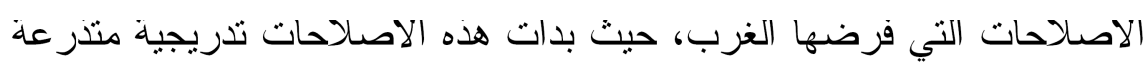
تارة بحقوق الاقليات الدينية في الامبر اطورية واخرى بحرية التجارة و الباب المفتوح و انتهى الامر بتفكيك الامبر اطورية و اضعافها وتقسيم و لاياتها بين القوى الغربية الكبرى نذاك... صحيح ان العرب حاليا لا يمتلون امبر اطورية او دولة واحدة موحدة ولكن الاخطار الني يمكن ان تترنب على تكرار ونو الي هذه الضغوط السياسية و العسكرية قد تستهدف تعميق الانقسامات المذهبية و الطائفبة

$$
\text { و الجغر افية و انفلات النزعات العرقية و القبلبة( آس). }
$$

ففي يوم 0 ايلول سبتمبر عام 9ب91، وقف ارسنيد برياند، رئيس وزراء فرنسا، في عصبة الامم في جنيف، ووجه دعوة حارة الى تحقيق وحدة اوربا

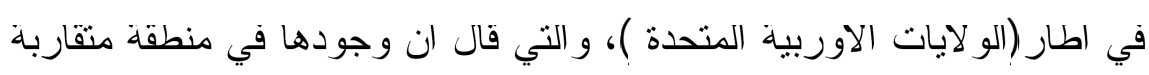

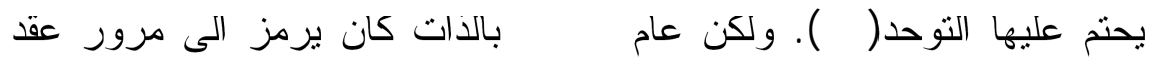
و احد من الزمن فقط على تطاحن الامم الاوربية في الحرب العالمية الاولى، و هو يقع ايضا قبل عقد واحد في عودتها الى النطاحن في الحرب العالمبة التانية. كما انه يقع قبل نتلاثة عقود طويلة من شروعها في اول مشروع اوربي مشترك للحديد والصلب عام 190V، حيث بدات اولى خطوات الوحدة

$$
\text { الاوربية(سب). }
$$

ان الفكر النقدي والاصلاحي العربي قد سبق بكتبر المقترحات الامريكية

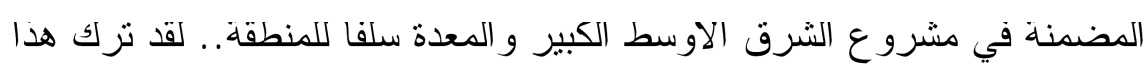
الفكر الاصلاحي و النقدي ميراتا فكريا منميزا حول حال الامة ومستقبلها و احتباجاتها النهضوية في كافة المجالات السياسية والاقتصادية و الاجنماعية وساهم في بلورته كافة المتقفين من كل الوان الطيف السياسي و الفكري ومن 
مختلف التبار ات التي جاهدت عبر موجات متتالية من النقد الذاتي و الموضوعي للمجتمعات و النظم العربية ورسمت مجتمعة خطوط الاصلاح ومعالمه و مضمونه و مبادئه.

إن تكاثر المبادرات الامريكية وغيرها في هذه الاونة ينبني ان يعيد

الاعتبار لمساهمات المتقفين و المفكرين العرب لانهم كانوا اسبق في ناكيد الحاجة للاصلاح و التغيير وتعيين حدودهما على كافة الاصعدة القانونية و السياسية والتقافية و الاقتصادية وربما ن الاوان لكي تسنكهم السياسات العربية دلك الرصيد الحقيقي الذي بمثل ويكرس دور منقفي هده الامة في نهضتها وهو على اي حال دور ليس جديدا لا في السياسة ولا في التقافة العربية بل هو قائم منذ نحو قرنين او ما يفوق ذلك(عَ).

الإصلاحات والمجتمع المدني والسياسي

حذر تقرير التتمية البشرية العربية لعام ع · · من ان ازمة التتمية في الوطن العربي من الجسامة و التعقيد ونتشابك الجوانب، بحيث اصبح اي إصلاح لإحدى النواحي المطلوبة لبناء نهضة إنسانية في المنطقة بسنلزم ان بمند إلى جنبات المجتمعات العربية كلفة.ويضيف التقريز ان الإصلاح الجزئي لم يعد كافيا مهما نعددت مجالاته، وربما لم يعد ممكنا من الاساس بسبب احتياج الإصلاح الجزئي الفعال لبيئة مجتمعية حاضنة، وان الإصلاح المجتمعي الثامل في البلدان العربية لم يعد بحتمل الإبطاء او النباطؤ .ويستعرض التقرير ابرز

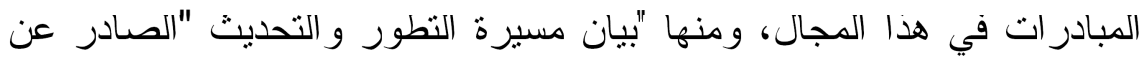

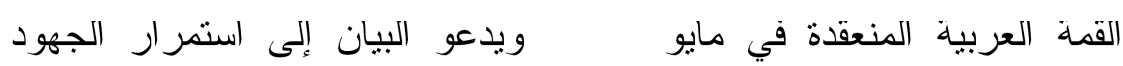
وتكتيفها لمواصلة مسيرة النطوير العربية في المجالات السياسبة والاقتصادية و الاجتماعبة والنزبوية(ro)، كما بدعو البيان إلى تعميق اسس الديمقر اطبة 
و الثُورى، وتوسيع المشاركة السياسية في إطار سيادة القانون، و إلى تحقيق

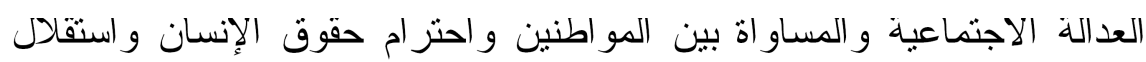
القضاء. كما يشير التقرير إلى إعلان صنعاء ووتثقة الإسكندرية. لقد قام الفكر السياسي و القانوني الجديد في دائرة الحضارة الغربية منذ القرن التالث عشر حتى قيام الثورنين الامريكية و الفرنسية في القرن الثامن عشر، بصياغة مبادئ و استنباط مؤسسات وتطوير اليات وتوظيف ادو ات حكم جديدة. وينطرق النقرير إلى مضمون الإصلاح المطلوب في البنية المجنمعية العربية على النحو التالي: يتطلب قيام مجنمع الحرية و الحكم الصالح إصلاحا منكاملا لنسق الحكم في تلاتة نطاقات منز ابطة: الإصلاح الداخلي، ويشترط إصلاحا مؤسسيا للاولة وللمجتمع المدني و القطاع الخاص لتعزيز مبادئ الإدارة الرشيدة، كما بتطلب تصحيحا لمسار النتمبة و إصلاحا سياسيا بشنمل على ولى إصلاح الممارسات، و الإصلاح القانوني، و إصلاح البنبة السياسية. اما الإصلاحح على المستوى الإقليمي فيعني الانتقال من نسق الحكم الإقليمي القاصر القائم حاليا إلى تتويعة من نرتيبات الحكم الإقليمي المتجهة نحو التكامل(7س). كانت التتظيمات الاقتصادية، اي كل ما بتعلق بتحديد علاقات العمل لهل و الانتاج في مسنو اها المعاش، التجارة و الصناعة و الحرفة و الزر اعة، تمتل شانا خاصا تم اصبحت تتضمن مستوى سياسيا عندما فرضت الحاجة الحضارية تدخل الدولة في هذه الحياة الاقتصادية. فالسياسة العامة الني تتنهجها الدولة في معالجة المشاكل المختلفة وتحقيق الرفاهية لافر اد المجنمع تتضمن مجموعة من

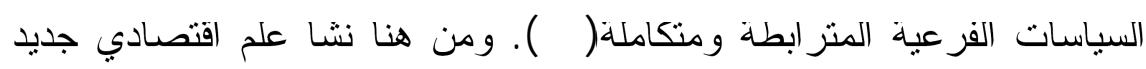

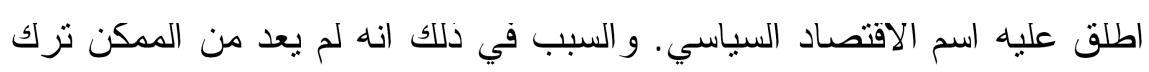
تتظيم الحياة الانتاجية في المجتمعات الني زادت تعقيدا لقانون او منطق بعن 


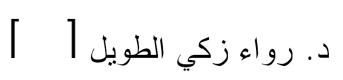

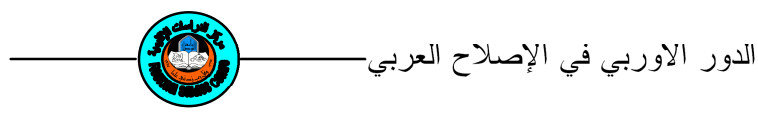

التضامن العفوي و الاخلاق العامة الاحسانية او الانانية، و اصبح تتظيم الاقتصاد

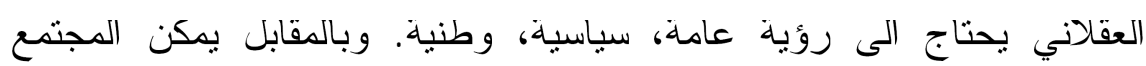
المدني ان يكون مصدر ا لقيم المحافظة و الرجعية متلما يمكن ان يكون مصدر ا

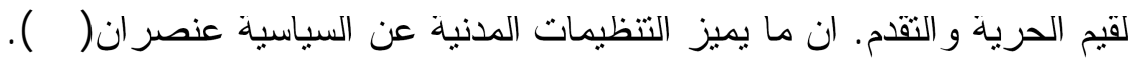
I. النتظيمات السياسية مركزية، اي تختص بتكوين السلطة المركزية وحمايتها بينما تقوم التنظيمات المدنية على الخصوصية والاسنقلالبة الذاتية وتتمية التضامنات الجزئية، اي انها نتطبق على نشاطات لاتتخل السلطة المركزية في تتظيمها المباشر. r. ان التنظيمات السياسية رسمية تبنى فيها العلاقات على اساس قانون تابت وعام ومجرد وموضوعي، في حين ان التنظيمات المدنية تخضع لقو اعد غير مرسمة، رهينة بصورة اكبر لتبدل ميزان القوى او العادة او الاخلاق او المصلحة. وهذا لايعني ان التنظيمات المدنية لاتقوم بالقسر و الضبط الدقيق لسلوك الافراد، ولكن طريقة تكوين السلطة

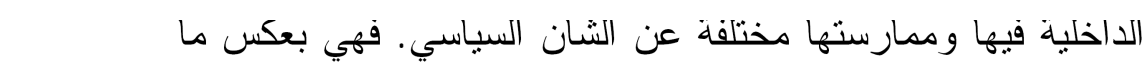
الدولة وتكوين السلطة المركزية، لا تخضع المؤسسات الني تعبر عنها لقو اعد و احدة مقننة من قبل السلطة المركزية وولاتنطبق على الجميع او لاتطبق

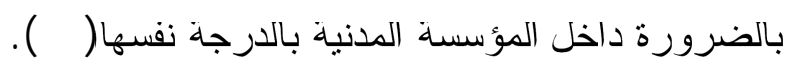
على هذا الاساس تعتبر مدنبة كل التنظيمات الاقتصادية او التقافية او الدينية الني تغطي ساحة النشاط الحر، غبر المنظم بنظام واحد وعام من قبل السلطة، و الدي بسمح لها النشاط بالنمو و التتافس و التجدد و الابداع. و لا تعني الحرية هنا ان الفرد لاسلطة عليه غير نفسه، ولكنه يشير الى نمط مختلف من السلطة وطريقة ممارستها و ادوات العقوبة و الجزاء الني ترتبط بها بالمقاربة مع النمط السباسي للسلطة. وكذلك لايعني عدم تطبيق قانون عام ان التنظبمات المدنبة 
لاتخضع لقو اعد وقوانين خاصة، ولكنها ليست شكلية ومرسمة كقوانين الدولنة( • ع).

لكن في جميع ذلك يتمبز نشاط السلطة في التنظيمات المدنية بانه اكثر مرونة وتعددية، ويرتبط بعوامل عدة منبدلة، منل الظروف التي تمارس فيها و التقدير ات الشخصية للقادة وقوة العلاقات الشخصية وجادبية المصالح المادية، انها تنظيمات شديدة المرونة وقابلة للتاقلم بشكل افضل مع الظروف و الاوضاع المتبدلة في الزمان المكان، وبذلك لايمكن الاستغناء عنها، في حين بشكل التبات و التجريد و العمومية وعدم التمبيز في النطبيق شرطا تعريفيا من شروط السلطة

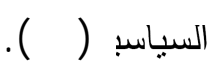

فهدف السياسة كما قلنا ومبرر وجودها هو ان تساعد المجتمع المدني على تجاوز تشتته وتتاقضاته، لا انكار قيمه وتتظيماته او فرض نمادج و انماط جاهزة عليه لايعرف اين يقيمها او يجد لها المكان و المجال بين بناه القائمة، ان ولهان ادخال انماط جديدة في مجتمع ما يتوقف على النجاح في معالجة البنى القائمة و افساح المجال او خلق شروط نمو هذه الانماط، وفي مقدنها انماط السياسة

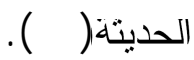

لكن المهم في كل ذلك هو ادر اك حقبقة اساسية وجوهرية هي ان الدولة و المجتمع المدني ليسا امرين مستقلين و احدهما عن الاخر، ولكنهما منر ابطان كليا. ان لكل دولة ولكل نظام سياسي المجتمع المدني الذي يتملثع معه. بل ان ان المجتمع المدني هو جزء من السياسة بمعناها الواسع و العميق، اي ان من غير ئري الممكن فهم مصبر المجنمع المدني في الوطن العربي وناثير العو امل و الخارجية ونه فيه من دون فهم تطور الدولة الحديثة وعلاقتها بالمجنمع. فالمجنمع المدني كالسياسة علاقة نكرسها سلطة معنوية او سباسية تضبط سلوك الافراد 


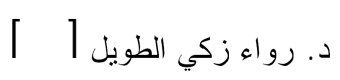

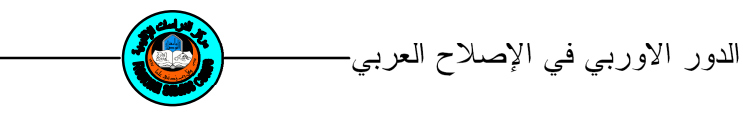

و الجماعات، فالحق في تقرير المصبر هو فعليا الحق المشترك في تقرير المصبر (بع).

\section{الاصلاح والتغيير في الوطن العربي}

من المستحيل تقسير الاوضاع السباسية في العالم العربي، بل والإسلامي كله، بمعزل عن العوامل الخارجية. ومدى مشروعية تدخل الغرب في النطور السياسي الداخلي للبلاد العربية. البعد التناريخي مهم جدا. فلو بدانا من منتصف القرن التاسع عشر منتا، اي من ذروة انحدار الدولة العتمانية بستحيل تفسبر النطورات التي حدتث في العالم العربي والإسلامي بانفصال عن العالم الاوروبي وعن الندخلات الخارجية. التي تقسر كل شيء في العالم الثالث بالاقتصاد وبالمصالح الاقتصادية الغربية، و افضل الناويل هو السياسي للوقائع. إن السياسة والثذخل الاستعماري اوجد كيانات الدول العربية الحديثة كالعراق

$$
\text { وسوريا ولبنان و الاردن وسو اها(عع). }
$$

هذا التعامل الخلاق قد يتاتى عبر إعادة الاعتبار لكل من طرفي هذه المعادلة اي تسوية الصر اع العربي الإسر ائبلي و البدء في الإصلاح و التغيير، اي ان هاتين المعضلتين تحظيان بذات الاولوية في جدول الاعمال العربي

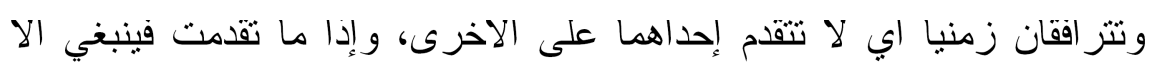
يكون ذلك على حساب التانبة، ابي باختصار تؤكد قدتها على إحداث قطيعة بمعنى من المعاني، مع خبرة الماضي المنز اكمة و الجامدة الني افضت إلى

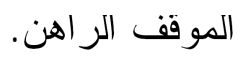

وذلك لا يعني بالضرورة تقليص مكانة القضية الفلسطينية وتسوية الصر اع العربي الإسر ائيلي بل يعني بلورة صياغة نظرية ومنهجية مضمونها ان الإصلاح و التغيير ينبغي ان يعزز ويدعم تصدر القضية الفلسطينبة و التسوية 
جدول الاعمال العربي، وان تخلق ديناميكية التغيير والإصلاح شروطا إقليمية وعربية ودولية تقضي في نهاية التحليل إلى تعزيز قدرة العرب الجماعبة

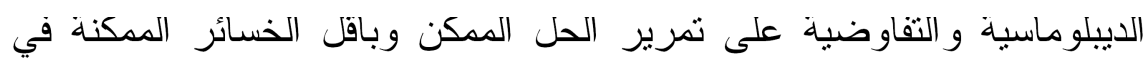
السياق الحالي. و لاشك ان إعادة تاسيس هذه المعادلة على هذا النحو تبدو اكتر جدة وجدية من تلك الحجج التقلبدية منل "رفض التغيير الو افد من الخارج" او ولئ

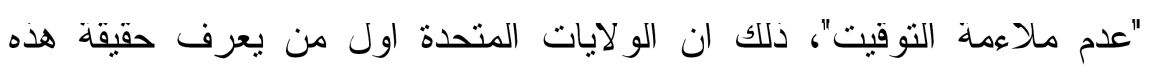
الحجج ووظيفتها في الماضي و الحاضر، فهي تعرف ان جو هر هذه الحجج هو

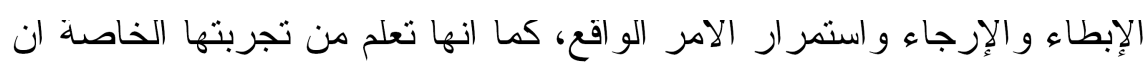
بناء الديمقراطية هو عملية داخلية سياسية طويلة تثشكل تاريخيا وليس وفق جدول زمني مفروض من الخارج. بل تعلم الو لايات المتحدة الامريكية اكتر من ذلك، فوفقا لدراسة اعدنها مؤسسة كارنجي لابحاث السلام فإن من بين النظم النماني عشرة التي تغيرت على وقع القوة العسكرية الامريكية منذ الحرب العالمبة الثانية، خمسة منها فقط هي الني انجزت ديمقر اطية يعتد بها ومنماسكة نسبيا الا وهي المانيا و إيطاليا و اليابان، و الني توفرت فيها شروط مفتقدة في كتير من دول العالم الني نريد

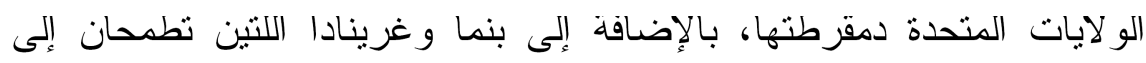

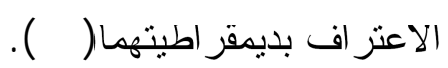

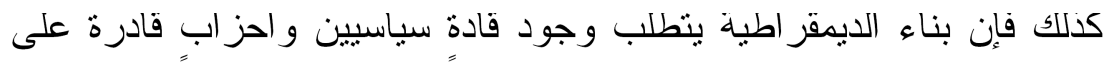
المنافسة بحرية وانتخابات مفتوحة وحرة. كما يتطلب فصلا بين السلطات، ومستوى اقل من الفساد وحماية للاقليات وحرية التتظيم والاجتماع و التعبير وصحافة حرة وهي عمليات بطبيعتها لا تتم بين عشية وضحاها بل بحاجة

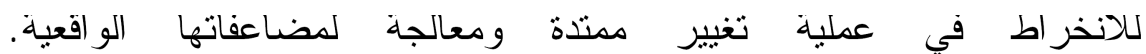


وهذه الشروط السابقة عندما تكون مفتقدة فإن المطالبة بالديمقر اطبة من

قبل القوى الكبرى وخاصة الولايات المتحدة الامريكية ستتخذ طابعا انتخابيا

داخليا بل وستخفض سقف الديمقر اطية حتى يتو اءم مع المنافسة الانتخابية.

فحينما تتانرت بقايا غبار معارك الحرب العالمية الاولى لم ينبق في سمع

شعوب الشرق الاوسط بالذات غير همسات خافنة من حرية.عدالة. مساو اة ولم

يكن من سمع بالديمقر اطية بمفهومها المعاصر الا من بعض من شاهد اوربا

وعرف شيئًا عن ذلك ؛ النمط من الاصلاح السياسي في العشرينات من القرن

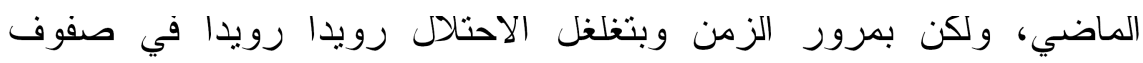

المجتمع اخذت كلمة الديمقر اطبة تعني النطور الاجتماعي اولا ومن ثم اخذت طريقها الى المظهر العام السباسي؛ العامر شكلية و الناقص اهلية؛ فالبلاط و الحكومة والبرلمان لم تؤسس وفق معايير سياسية تثكن هن النفاذ الى المجتمع وتصبح جز ءا من نكويناته وسلوكياته المتطورة؛ و انما ار اد بها المحتل ان تكون صورة مصغرة تنظر اليها عصبة الامح على انها انجاز متكامل

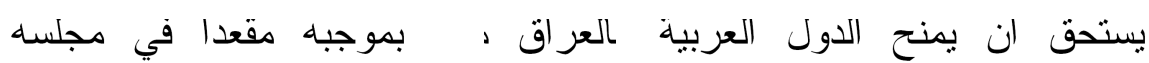

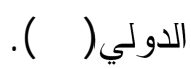

ان الدور الخارجي في التاتير على الاوضاع الداخلية هو احد حقائق السباسة في المنطقة العربية. و الدلائل على ذلك كتبرة، سواء منها ما بتعلق الق بالناريخ الحديث او بالاوضاع الراهنة. ولا يتعلق بهذا المعطى بل باشكال النذخل ووظائفه.ان للضغط الخارجي على النخب الحاكمة فعالبة لان هده الاخيرة تمثلك شعور ا بانها تسنمد شر عيتها من رضا الخارج عنها، مما يضعه امام مسئولبة كبيرة. و التنخل المفيد و المطلوب ليس عسكريا و لا مالبا بل هو به معنوي، يختص بنوفير فسحة من الحريات وبتقليص الميل القعي للانظمة 
و الدور الاوروبي في دعم التورة العربية الكبرى معروف: "النتريف حسين" في وجه الاتز اك. كما دعم الاوروبيون مشروع إنشاء الدولة السعودية. لا يمكن فصل الاحداث الكبرى المتعلقة بالنطور ات السباسبة في البلاد العربية عن العنصر الاستعماري: فقد اتت بريطانيا والقوى الاوروبية بمشروع تقسيم فلسطين و اقامت إسرائيل وسط العالم العربي. اكتر من ذلك، وضعت

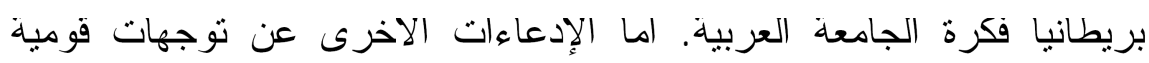
عربية في تفسبر نشوء الجامعة فيجب ابقاؤها في حجمها الحقبقي. لقد ارادت بريطانيا تحقيق نوع من الموازنة مع خلق إسر ائيل في فلسطين، فاعطت و عد

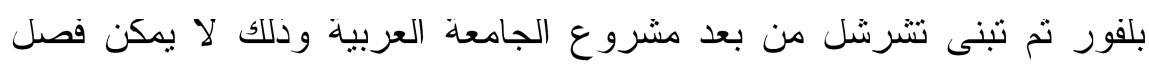

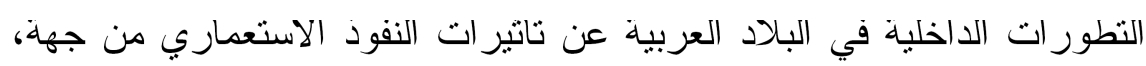

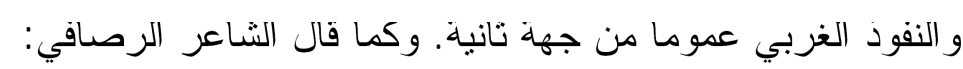

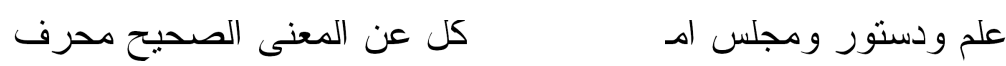

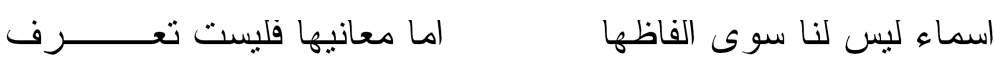

و هكذا كانت صورة الديمقر اطبة امام المجنمع العر اقي. ومع ذلك فقد رضي الشعب بها مظهر ا؛ نم اخذ الوطنيون بطورون موقفهم منها لوضعها على قاعدة النطبيق العملي؛ فماكادت العشرينات من القرن الماضي ناذن بالانصر اف حتى اخذت صيغ الديمقر اطية السياسية تتغلغل في مفاهيم الطبقة المتقفة عن طريق بالتئ

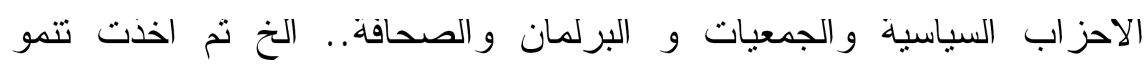
وتتشط في اوساط اخرى كالمدارس الثانوية و الكليات و النقابات العمالية

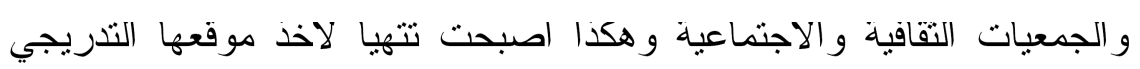
في الاسرة و القرية و المدينة(عV). 


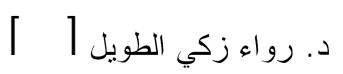

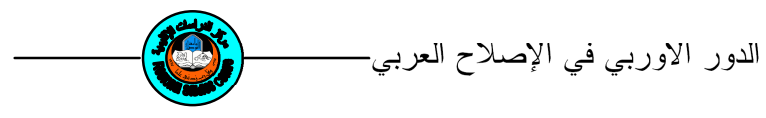

وقد عمل الساسة الوطنيون بكل طاقاتهم لنرسيخ قو اعدها وتقكيك ما

يحول دون استقرارها لتكون نمطا من الثقالبد المتداولة سياسيا ؛ وما هي الا سنوات قليلة جدا حتى جاء الانقلاب العسكري الاول عام 7سو1 ليقوض الاسس وليبدل المفاهيم التى كانت في بدايتها التنريجية الايجابية الاولى التي لو قيض لها النمو و الازدهار بشكل طبيعي خارج دائرة العنف والانقلابات و التقانل على السلطةو بصيغ غير مشروعة و لا ديمقر اطية، لتجنبنا كتيرا من الكوارث و المصائب الني مرت، ولمنع هذا التثهور و النز اجع الى الخلف الذي

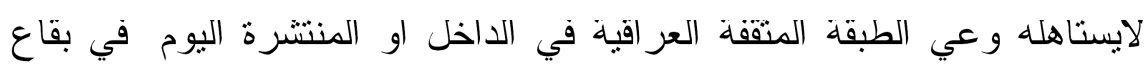
الارض و الني نسهم في رفد الحياة الانسانبة. تعطي صورة مصغرة و اقعية عن خلفية ما عرف سابقا وما اصبح عليه الوضع الحالي. مع ثتابع الانفجارات السياسية والامنية في المنطفة، ومع الدخول الامريكي و البريطاني الكبير عسكريا وسياسيا و إعلاميا على هذا الجزء هن الهن العالم، اصبحت الدراسات الني تصدرها مر اكز الابحاث الغربية و الدوريات و المطبو عات غزيرة ومتتو عة. هذه الدراسات منفاوتة في موضو عيتها او في

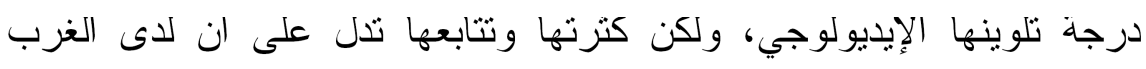

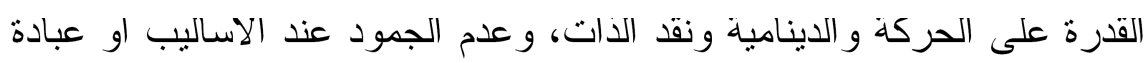
الاسلوب، لبس من اجل ان البحث عن الحقيقة فضيلة وحسب، بل لان الحقيقة

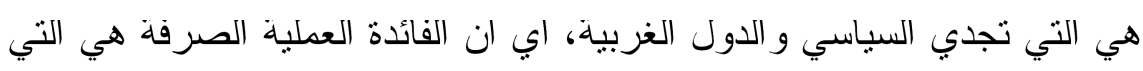
تقود عملية البحث عن القز اءة الصحيحة، او محاولة الوصول الى هده القراعة. إن عصر الهيمنة الامريكية في منطقة الشرق الاوسط قد انتهى وبدات مرحلة جديدة. ويعتقد ان تشكيل المرحلة الجديدة سيعتمد على عناصر جديدة ومنعددة للنانير على منطقة الثرق الاوسط، الامر الذي يعني ان على الولايات 
المتحدة ان تعتمد على الدبلوماسية وليس على اليد العسكرية للمحافظة على

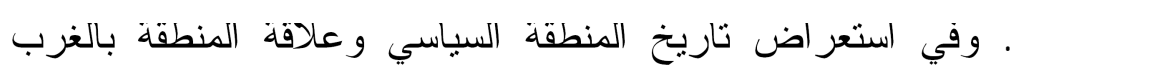
نستذكر انهيار الدولة العثمانية في نهاية الحرب العالمية الاولى، ثم مرحلة الاستعمارين الفرنسي والانكليزي الى لحظة انتهاء الحرب العالمية التانية وما لهابه صاحبها من صعود الوعي القومي والمرحلة السياسية القومبة في المنطقة العربية بكل احلامها وعنفو انها، تم مرحلة الحرب الباردة بين المعسكرين الثرقي و الغربي، نم مرحلة حرب $197 V$ وما بعدها، و إدر اك الغرب، و الر اي العام فيه، لمدى اهمية المنطقة من منظور الامن الافتصادي باعنبار النفط هو

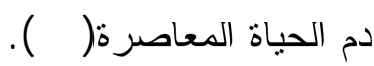
ان انعقاد القمة العربية في تونس، في ظروف بالغة الدقة و الحساسية، وكانت انظار المواطنين العرب في كافة الاقطار العربية، إلى هذه القمة

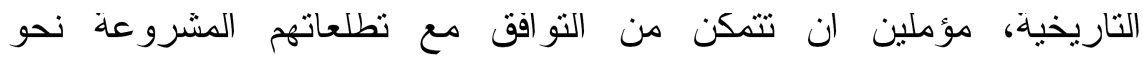
الديمقر اطية و الإصلاح و التغيير و احتو اء الضغوط الو افدة من الخارج. اما من ناحية النوقيت و الظروف السياسية لاعمال هذه القمة وقرار اتها المرتقبة، فإنها تثميز بمعالم و اضحة ومعطبات محددة، ليس بمقدور القمة تجاوزها او تجاهلها، بل ينبغى ان تؤخذ بعين الاعتبار، فتوقيت القمة العربية في تونس تزامن مع تسريب مبادرة الثرق الاوسط الكبير و المبادرة الاوروبية حول إصلاح الشرق الاوسط، ودمقرطة نظمه السياسية وتعديل نظمه الاقتصادية والتقافية، ويفصل نوقيت عقد القمة العربية شهران عن عقد القمم التناث الاخرى، التي وهي قمة الاطلسي الني عقدت في اسطنبول و الني تبحث مبادرة الشرق الاوسط الكبير بمشاركة اوروبية، وقمة الدول الصناعبة والقمة الاوروبية الامريكية كما ان توقيت عقد القمة العربية يفصله ايضا شهران عن 
د. دواء زكي الطويل]

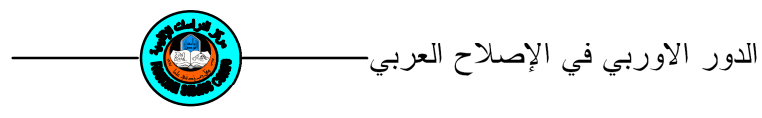

موعد تسليم السلطة للعر اقيين واجر اء انتخابات الرئاسة الافغانبة، و لايخفى مدلول هذه النوقبتات و الاحداث المتز امنة، في ما بتعلق بعقد القمة العربية، فكان المطلوب من القمة ان تتخرط في مضمون هذه التوقيتات و المو اعيد من زاوية قرار اتها التي ستصدر ها، بل وكان القمة العربية لا تعدو ان تكون موعدا كونيا للإصلاح و التغيير، على غرار هذه القمم التي تتصب اعمالها حول بند التغيير في الشرق الاوسط كبير ا كان ام صغير ا. ومن ناحية الظروف السياسية الني انعقدت فيها القمة فتمة سيل منهمر من المبادرات و الافكار حول الإصلاح ومضمونه وسبل إجرائه، فمن ناحية المبادرة الامريكية و المشروع الاوروبى ومن ناحية اخرى المشروعات العربية للإصلاح سواء تعلق الامر بإصلاح الجامعة العربية او الإصلاح الداخلي، او الونيه

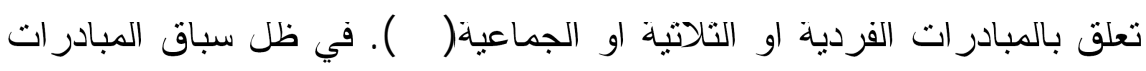
و افكار الإصلاح، وبصرف النظر عن المفاضلة بينها او التذقيق في محتو اها ومضمونها، فالامر المؤكد ان هاجس الإصلاح والنطلع إليه اصبح معيارا

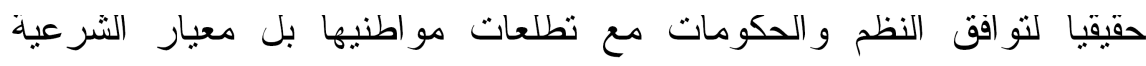
و الاستمرار، و اصبح مطلب الإصلاح و التغيير معيار ا لنقويم قرارات القمة ونجاحها في الوقت ذاته، ذلك ان خطاب ومفردات الإصداح السباسى و التغيير اصبحت نتخل بؤرة التفكير في العالم العربي الشعبي و الرسمي. مع نهاية الحرب الباردة، اصبح النفوذ الامريكي في ذرونه، وتجلى ذلك بك النفود في حرب الكويت... تم السعي الامريكي الحتبث لعملية السلام بين

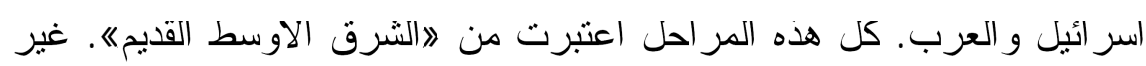
ان هذا النرق الاوسط القديم بدا بالتغير، ومن ابرز محطات تغيره قرار

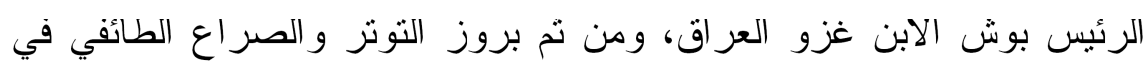


العراق وخارجه. ان سقوط نظام الثرق الاوسط القديم كان بسبب الانظمة العربية الحاكمة ونركيا الكمالية و إيران الثاه التي لم تقلح في الصمود امام احزاب الاسلام السياسي، وتعبث كثير ا في منازلة ومصارعة هذه الاحز اب الاسلامية، التي تضع البرنامج السياسي في \النو اة/كن مشرو عها. ومما ساعد على تفتي تاثبر الإسلام السباسي، هو حالة العولمة الني سهلث الحركة و التو اصل بين هذه الجماعات، و ايضا الانتشار الاعلامي و انحلال قبضة الدولنة

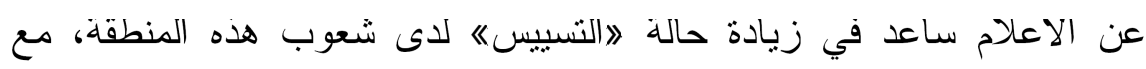
الدفق الاعلامي و الصور المتلاحقة عن الحرب في العراق ولبنان وفلسطين. ويتوقع الخبراء ان امريكا، ورغم هذا كله، سوف نظل اللاعب الاكبر في المنطقة، لكن سوف تدخل قوى اخرى تزاحمها منل روسيا و الصين

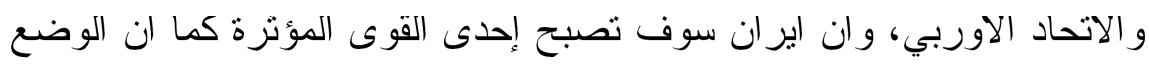
في العر اق سيستمر على ترديه وسيصبر مركز ا للصر اع يؤنز على جواره. و اسعار النفط ستصعد اكتر وصولا الى سعر مائة دولار نظر الزيادة الطلب

$$
\text { من الهند و الصين. }
$$

ان هذا بعني زيادة هائلة في المداخيل للدول المنتجة للنفط و على راسها السعودية وإيران، وسبؤدي هذا، مع توثز المنطقة، الى سباق نسلح و انفاق عسكري عال لدول المنطقة. كما ان ذلك الصعود و الاستمر ار في زيادة الضغط لونط الاجنماعي و السياسي، مع افكار مثل فكرة صراع الحضار ات لصمويل هنتجنون، او نهاية التاريخ لفزانسيس فوكوياما بدات بمقالات نشرت في مطبوعات منل شؤون خارجية. ربما تصبح هذه الافكار و النصور بات قائدة

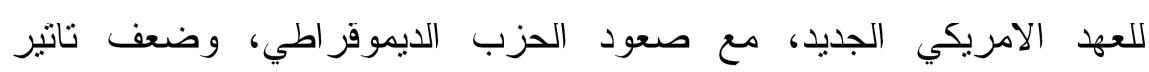

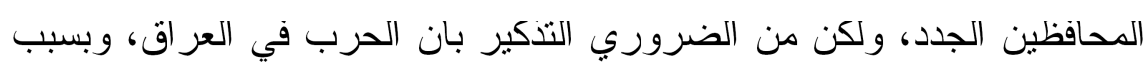




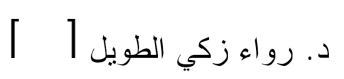

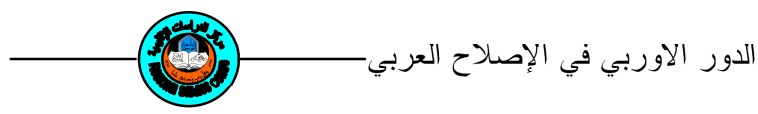

الاخطاء التي ارتكبتها الادارة الامريكية في استثمار النصر، هي الني تقود هذا الجدل في اوساط الباحتنن و المفكرين في امريكا، كما ان السجال حول تعريف وتشخيص الوضع الامريكي في العراق تحول الى مادة جدال سياسي بين الحزبين، فهذه القضية، قضية العر اق، بعتبر ها الديموقر اطيون، قضية جمهورية

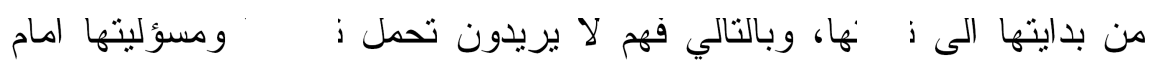
الناخب الامريكي. ان النقاش في الغرب حول موضوع النز ابط الاشتر اطي، وهل بمنلك القدرة على التاثير، وهل مفعوله سلبي او إيجابي، وهل بستنفد طاقات المجتمع قبل هول

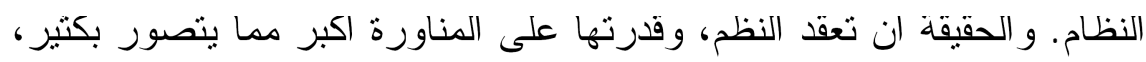
فهى نفسها اول من بعتمد على امريكا واول من يحرض ضد ولد امريكا. ان العقلية الامريكية و الاوروبية عقلية غير مركبة، تتعامل مع المسائل بمنطق بسيط، وهي بالتالي لا تقهم النعقبد والحيل الموجودة في العالم العربي و الثرق. هو عالم بحنوي على علاقات وتعقبدات بصعب على الغربيين إدر اكها. و الذي يحصل في العراق يدل على ذلك، ويوقعهم في الذهول. فخبرتهم لم تؤهلهم لنصور النعقيدات الموجودة في العر اق وهي نفسها موجودة في المنطقة

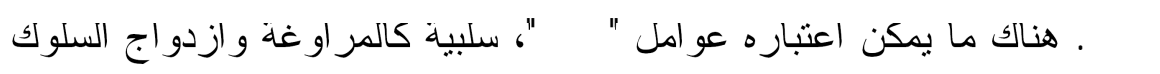
الشائع في مجنمعاتنا. لقد اسهم الغربيون في دلك إلى حد كبير، فهم حافظوا على هذه النظم ودعموها. فالوضع المحافظ المتخلف القائم في بلاد البترول لبس بحال مقطوع

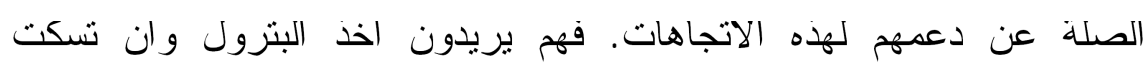
المجتمعات عن ذلك، فعملو ا بالتالي على حجز نموها الطبيعي. تحت دعاوى احتر ام الخصوصبة الحضارية، بتعايش في السعودية الان المباني الهائلة 
و المنشات الحديتة و النساء المنقبات المقهورات. وبعبارة اخرى، إذا تصورنا السعودية من غير بنزوول لكان باب مجنمع قد انفتح ولنزعت المراة ققابها.المشكلة ان التروة النفطبة حافظت على هذا المجتمع وجمدنه بهذا الشكل، برول و اصبح بالتالي مجتمعا مشوها بكل معنى الكلمة، وهو امر لا ينفصل اطلاقا عن اثر العنصر الخارجي. قبل ان بنزلق جورج بوش في مستنقع العراف احدث تصريح قيل في البيت الابيض، برفض ضرب المتظاهرات المصريات امام نقابة الصحفيين ويدينه، اتز ا معنويا كبير ا لدى الناس. فاكترهم عداء لامريكا اي اليساريين و الناصريين، كانو ا ر اضين.

لقد عصف عصر العولمة بعديد من مقومات السبادة و الاستقلال وخلق حالة تداخل كونية في الامن و المصالح السياسية والاستر اتيجية، و لابد ان نعي حدود الاستقلالية في الوقت الراهن وطبيعتها في اللحظة الحالية اما التعلل بخصوصية الاوضاع التقافية و الحضارية فهي حجة ليست في صالحنا إجمالا. فهل نعني هذه الخصوصية الإبقاء على تردي اوضاعنا السياسية و الاقتصادية و الاجنماعية و العلمية وتنني كافة مؤشرات التنمية المستدامة الاقتصادية و البشرية في ما بتعلق بالحجة القائلة باننا نعرف طريقنا إلى الإصلاح بافضل

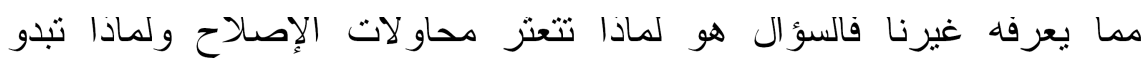
خطوات الإصلاح تقبلة باكثر مما ينبغي بل ولماذا ينت تقريغ بعض الخطوات

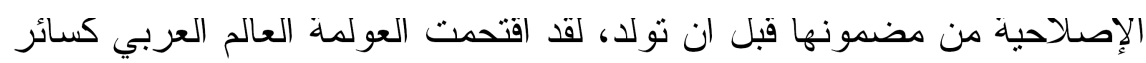
مناطق العالم وتركت ثاتثر ها في كل مناحي الحياة( - 0). ان الخطاب العربي الرسمي حول التغيير هو خطاب ثبريرى، ينطوي صر احة وضمنا على الإرجاء و التجاهل و الالتفاف حول المطالبة بالإصلاح، 


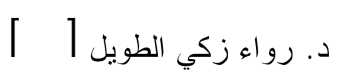

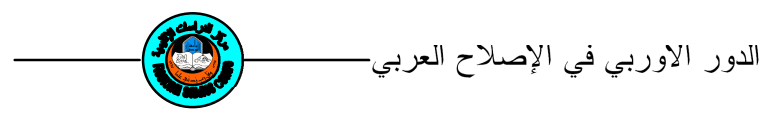

و هو ما فهمه الجميع في الداخل و الخارج. وذلك يقضني خطابا جديدا حديثا

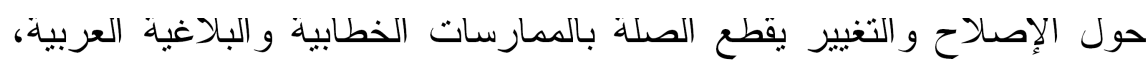
خطاب يتميز بالاصالة و الجدة و الجدية و الصدق في النعامل مع مطلب الإصلاح

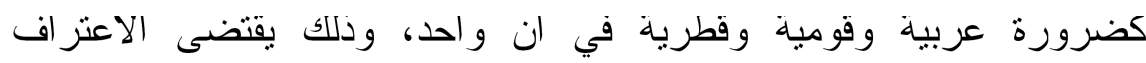

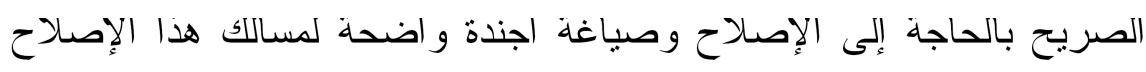

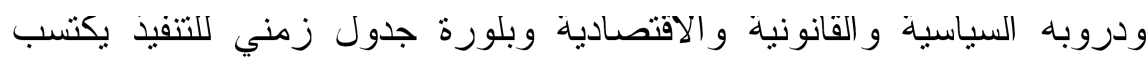
المصدافية الداخلية و الدولية اخذا في الاعتبار الظروف و الملائمات السياسية و الحاجات و العقبات المككنة بشرط الا يكون ذلك مرة اخرى تبريريا.

النتائج لم تكن مبادرة "الشر اكة الاوروبية المنوسطبة" الني نوجها إعلان "برشلونة"،

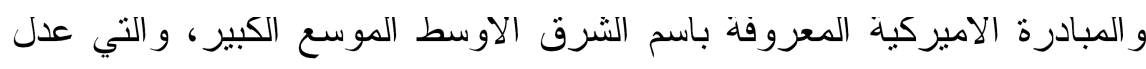

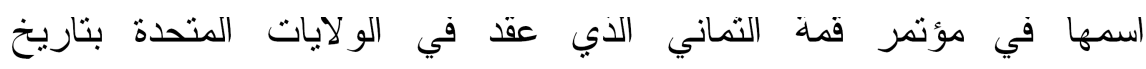

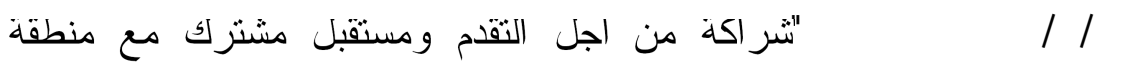

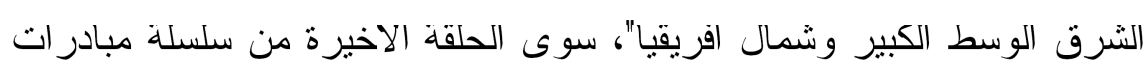

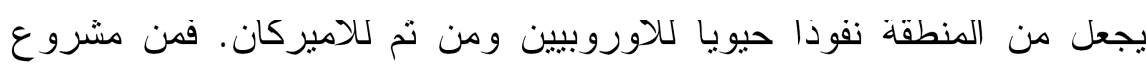
الثرق اوسطية إلى مؤتمر مدريد إلى مشروع منطقة التجارة الحرة الاميركية

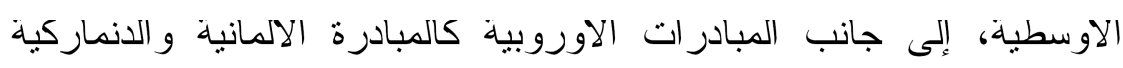

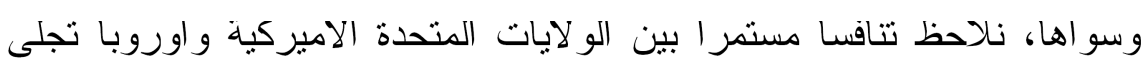
بصيغة مطالب او مبادر ات او حتى إملاءات تقرض على بلدان المنطقة انطلافا

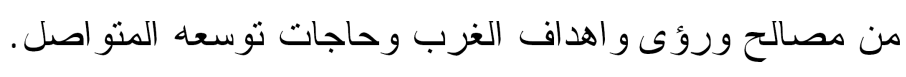
وكانت الانتقادات الموجهة إلى المبادرات الإصلاحية الخارجية، إن هذه

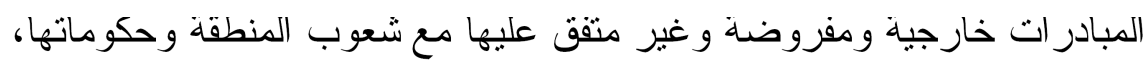


و إن كان النمبيز بين المبادرات الاوروبية والامبركية ضروريا هنا من خلال حرص اوروبي اوضح على تقهم قضايا المنطقة وما ينجم عنه من دور اوروبي اكتز توازنا إزاء مشكلات الصراع العربي الصهيوني والموقف من احتلال العر اق مقارنة بالموقف الاميركي. إلا ان التعديلات الني ادخلها الامبركيون بعد مؤتمر قمة التماني على مبادرتهم قد اسقطت ولو شكليا هذا الاعتر اض. إذ إله

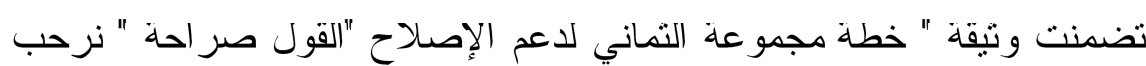
بالرغبة و النز ام مو اصلة التحديث اللذين عبر عنهما زعماء المنطقة" وذلك في هي إثنارة إلى القمة العربية في تونس. وتضيف الوتيقه" ومن خلال التشاور و الحوار مع زعماء و اشخاص في المنطقة، واستجابة لاولويات الإصلاح الني لئه حددتها المنطقة، بما في ذلك تلك التي حددتها جامعة الدول العربية، طوزرنا خطة اولية لدعم الإصلاح". وذلك من خلال إنشاء منبر للمستقبل يضم مسؤولين ووزر اءو وقوى مدنية من مؤسسات الاعمال يقدم عبرها المشاركون ار اءهم في الإصلاح ويعملون مع الحكومات على صعيد التتفيذ. و إذا كانت التعديلات السابقة قد اسقطت صفة الفرض و الخارجية عن المبادرة الامبركية ولو شكلبا، إلا ان الاعتبار ات الحققية الكامنة ور اءها ما زالت تعبَر في عمقها عن رؤية ومصالح الاخر وتعكس إلى حد بعبد وجهات نظره فيما يجب ان يكون علبه مستقبل المنطقة حتى تتلاءم مع المتغيرات المرغوبة ورلا تشكل عو ائق في لي طريقها. ولم تات المبادر ات نتيجة طبيعية لنطور حاجات تلك المجتمعات. و وهنا من المفبد ان نميزز بين الإصلاحات التي نمليها الضرور ات و المصالح الداخلية العربية، والني ظهرت ولو جزئبا بصيغ نوجهات او خطط إصلاحية في هذا 


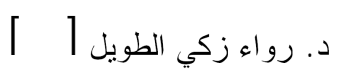

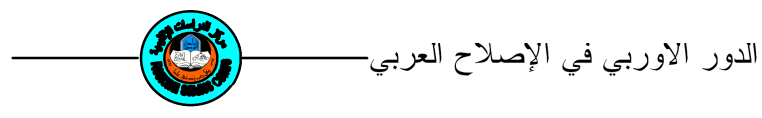

البلد العربي او ذاك(سورية، السعودية، المغرب، مصر)، وبين الإصلاحات الخارجية الني تحكمها اسس مختلفة.

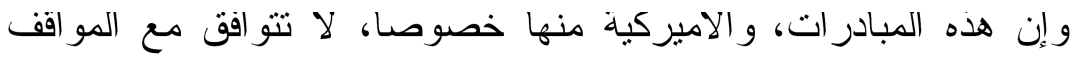

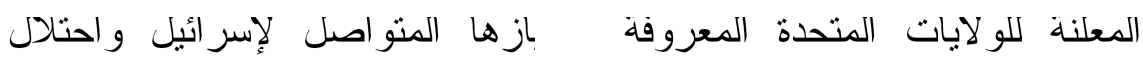
العراق، الامر الذي اضعف مصداقية اميركا وهزَ بعنف صورتها في المنطقة

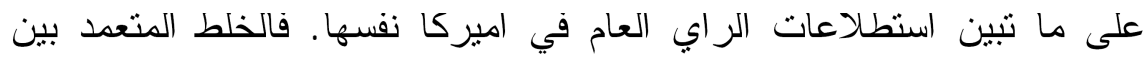
الإرهاب وحق الثُب في مقاومة الاحتلال و السيادة و الاسنقلال قد ادخل اميركا بقيادة المحافظين الجدد في تناقض جوهري مع حركات التحرر وحقوق الشعب

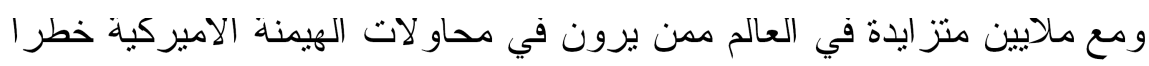
وجوديا يهدد انتماءهم الحضاري وهويتهم التقافية. وبعد ان كانت الو لايات المتحدة الامبركية حتى النصف الاول من القرن العشرين معروفة بدعمها

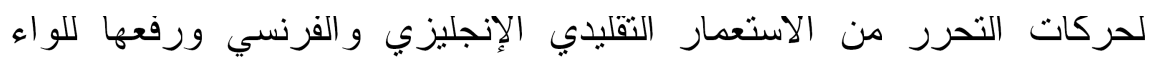

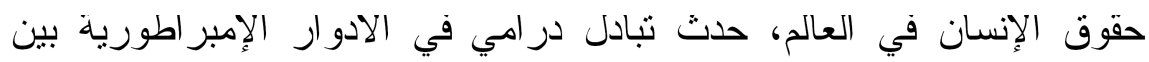

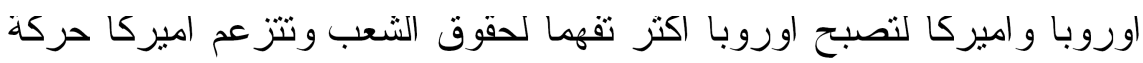
التوسع و الهيمنة بسبب تربعها على هرم القوة الاقتصادية و العسكرية في العالم.

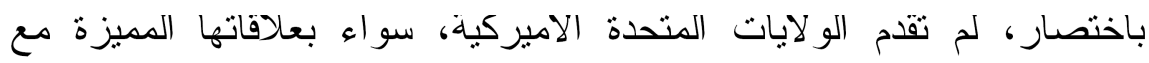
الانظمة العربية المغلقة و الحليفة لها، او من خلال مو اقفها المعلنة و المتحيَّة لإسر ائيل المنل او النموذج الذي يمكنها من حيازة المصداقية الضرورية لنجاح النياح مبادر اتها في المنطقة. ونلاحظ ان الموقف العربي من المبادر ات الخارجية بالنململ وعدم الوضوح

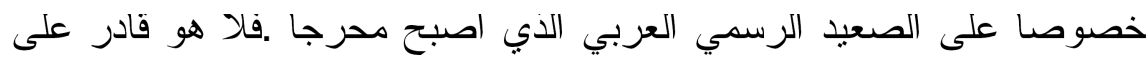

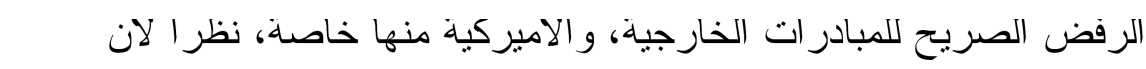


البلدان العربية تعتبر نفسها حليفة لو اشنطن بصيغة او باخرى، و لا يستطيع القبول بالمبادرات لاسباب تخص كل دولة عربية على حدة و لاسباب عامة ومشتركة بين البلدان العربية.

يجب ان نكون الاصداحات بمستوى التحديات و الامنيات الني تعلقها

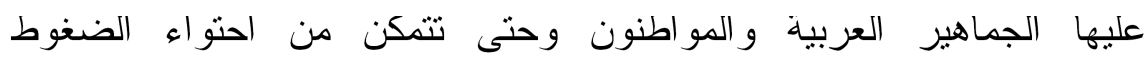
الامريكية والاوروبية، عليها ان تعبد النظر في الخطاب الرسمي حول التغيير و وهوبه في منطلقات ا لتغيير ومبادئه ومضمونه. رفض التغيير الو افد من الخارج وتاكيد الاستقلالبة العربية في مو اجهة هذا التغيير المصحوب بضغوط خارجية وخصوصية الاوضاع التقافية و الحضارية العربية، اننا نعرف طريقنا إلى الإصلاح و التغيير باكثر وبافضل مما بعرفه غبرنا، اي اولئك الغرباء عن منطقتنا. على الصعيد العربي العام فإنه بمقدور العرب ان بعيدو ا الحباة الى التكامل الاقتصادي العربي و البات العمل العربي المشنرك السباسية و العسكرية وان تزكز المحاولة على تلك القضايا التي تحظى بالاجماع و النو افق و ان تتجنب تلك القضايا التي نتير الخلاف. على العرب و العالم تجاوز التحديات الر اهنة لبس بالقفز فوقها و إنما معالجتها بطريقة تتلاعم والاوضاع العربية الراهنة وتعتمد مبدا التندرج في الاصلاح و الجدية في التتفيذ والالنز ام وتثكن من احتواء الضغوط الخارجية و الامريكية على نحو خاص وتاكبد قدرة الذات العربية و العقل السياسي العربي على مو اجهة معضلات النطور السياسي المحلي و العالمي، بينما ان العالم 


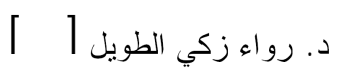

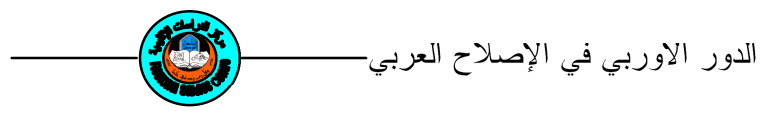

و الو لايات المتحدة واوروبا تطمح الى فرض شروطها ورؤاها للاصلاح في

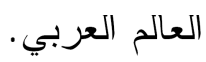

يجب الناكيد على ان نموذج التغيير والاصلاح المعد سلفا، في دوائر

الخارجية والديبلوماسية الامريكية يمنل حلم المحافظين الجدد و اداتهم لتامين الهيمنة الامريكية في المستقبل، ولكنه بالتاكيد لا بمثل نطلعات المواطنين

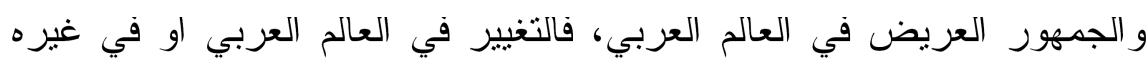
يرتبط بمشاركة و اسعة من قبل المو اطنين عبر اقنية ودروب سياسية وقانونية، يحميها القانون و الثرعية وتستتد الى قو اعد اجتماعية وتقافية راسخة ومن تم

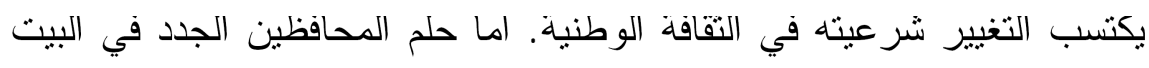

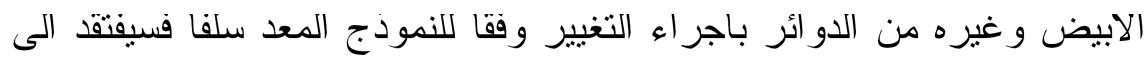

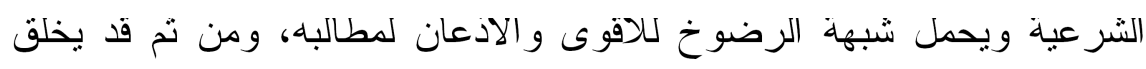

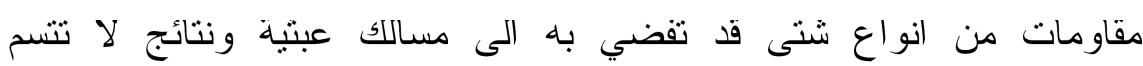

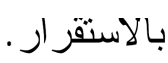

ان رفض نموذج "الشرق الاوسط الكبير الذي تقترحه الو لايات المتحدة

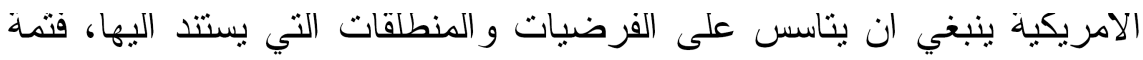

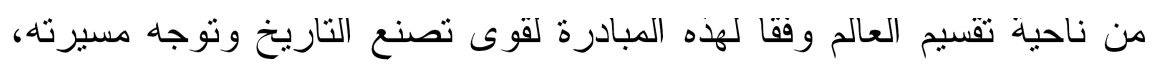
وقوى اخرى ليس امامها سوى ان تسير في الخط الذي رسمته هذه القوى

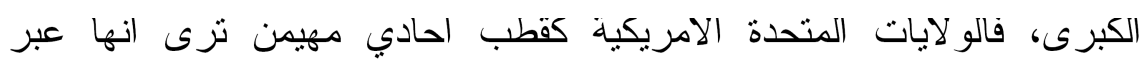

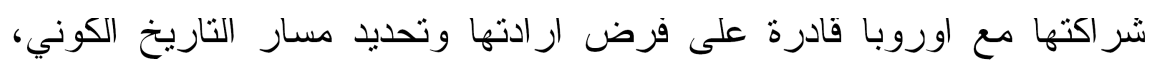

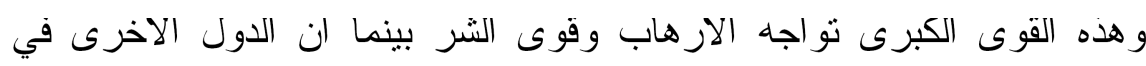

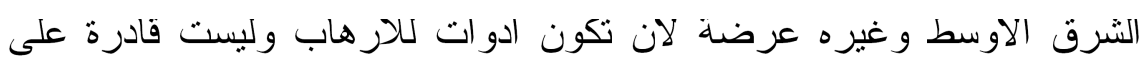

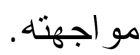




\title{
The European Role in the Reform in the Arab Homeland
}

\author{
Dr. Rawa Zeki Younis \\ Assistant Professor, Department of Economical And Social Studies, \\ Centre for Regional Studies, University of Mosul
}

\begin{abstract}
It is Impossible to explain developments that happened in the Arab and Islamic world separatedly the from the world, European and external interference. Which explains everything in the third world economy and Western economic interests, and the best interpretation of the facts is political. That politics and the interference of colonial entities created modern Arab states such as Iraq, Syria, Lebanon, Jordan and others.
\end{abstract}


1.David Miller, ed. , The Blackwell Encyclopadia of political thought Oxford, uk, New york, Blackwell , 1995.

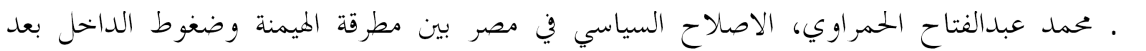

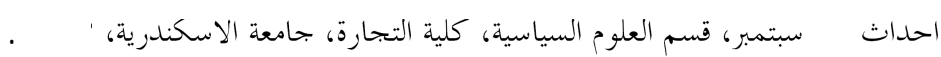

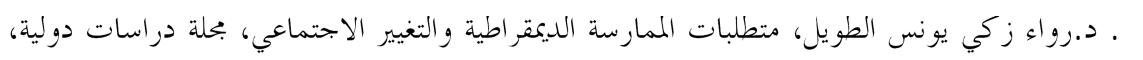

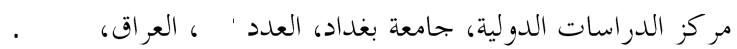

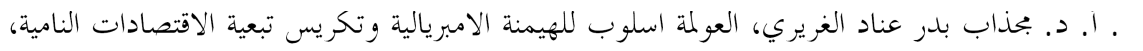

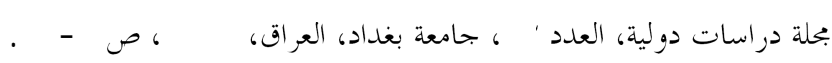

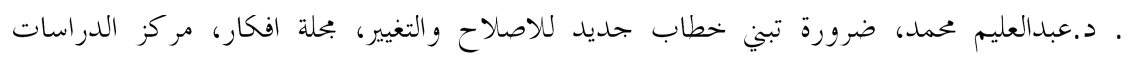

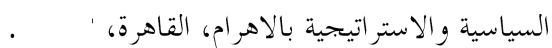

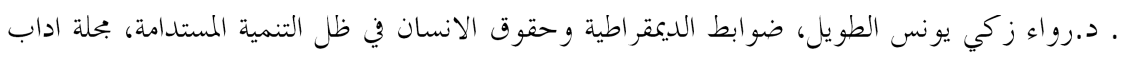

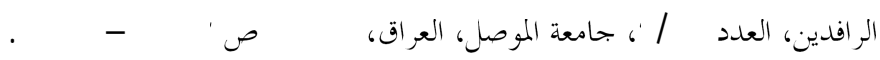

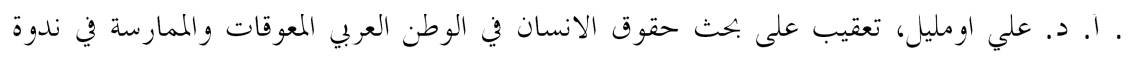

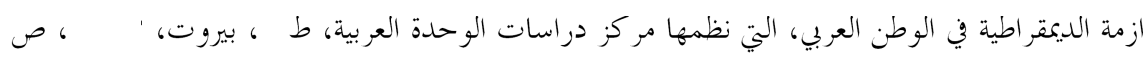

8. Tatu Vanhanen, prospects of Democracy, A study of 172 Countvies, New york, London, Routledge, 1997 , pp.28-31.

9. سعد الدين ابراهيم وانخرون، ازمة الديثقراطية في الوطن العربي، مركز دراسات الوحدة العربية،

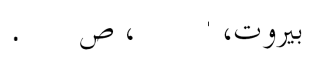

10. J. Denis Derdyshire and lan Derdyshire, spotlight on world political systems, An Introduction to Comparative Government, chamders Political Spotlights, Edinburgh , chambers, 1991, p.49.

$$
\begin{aligned}
& \text { | I. د. عبدالعليم محمد، مصدر سابق. }
\end{aligned}
$$

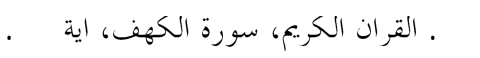

$$
\begin{aligned}
& \text { سا ـ الحمر اوي، مصدر سابق. }
\end{aligned}
$$


عا .القران الكريم، سورة الانبياء، اية I. 10. د.علي خليفة الكواري، مفهوم المواطنة في الدولة الديمقراطية، مركز دراسات الوحدة العربية،

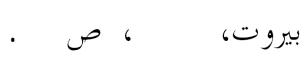

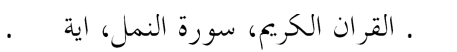
IV

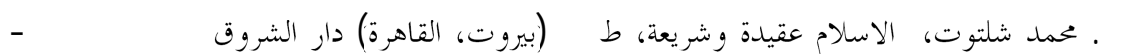

19. القران الكريع، سورة النساء، اية Oبرا.

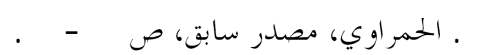
اب. خالد العسلي، الشرى في العرف القبلي، الشورى في مهكة قبل الاسلام، الخمع الملكي لبحوث

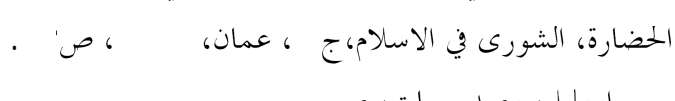

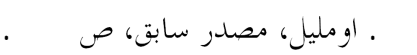
سب. د. عبد العليم محمد، مصدر سابق. 24. Waterbury, fortuitous Byproduct, lisa Anderson, ed, Transitions to Demoeracy, New york, Columbia University Press, 1999, p261.

TO. د.رواء زكي يونس الطويل، ابخاهات التطور التقيخ الالكتروفي في الدول العربية والنامية، بحلة كلية

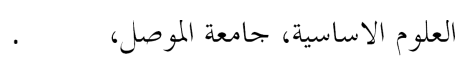
7. المعنى المضمر في الاصلاحات هو انقسام العالم لقوى تصنع التاريخ واخرى تسير فيه كرها.

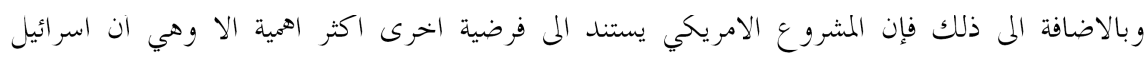

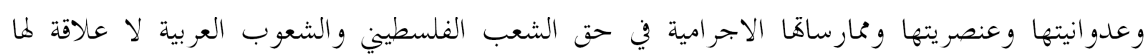

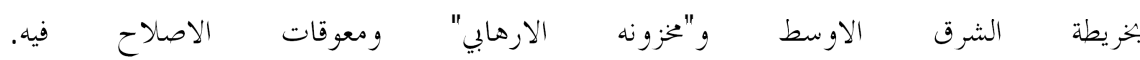
وينفي المشروع عن اسر ائيل اية قمة واية مسؤولية عن تعويق عملية البناء والدمقرطة والتطور في العالم العربي. MV 
א Y. في عهد الرئيس بوش الابن ومغامراته العسكرية في افغانستان والعراق على نحو خاص وتاسيس

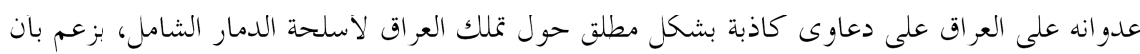
مغامرته في العراق كانت بحرد حلقة في مشروع كبير لتغيير العالم والشرق الاوسط الكبير تحديدا. وץ. د.محمد عابد الجابري، مسالة الهوية، العروبة والاسلام والغرب، ط ل، مركز دراسات الوحدة

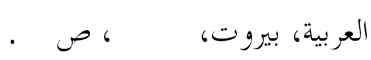

•س. د.محمد راتب الحلاق، غوايات العولمة وترهاتا، بحلة دراسات دولية، مركز الدراسات الدولية،

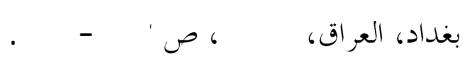

الا. .بما يهاد اسس وامكانات الحديث عن كيان عربي واحد او وحدة عربية ثقافية واقتصادية في

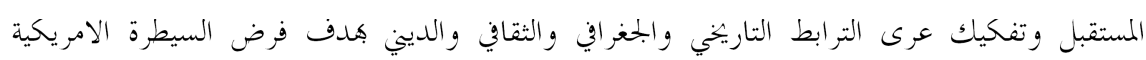
والاسر ائيلية على المنطقة. זس. د.علي خليفة الكواري، المسالة الديمقراطية في الوطن العربي، ط اله سلسلة كتب المستقبل العربي

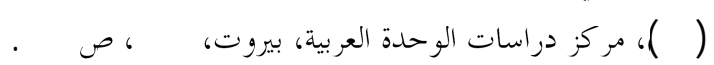

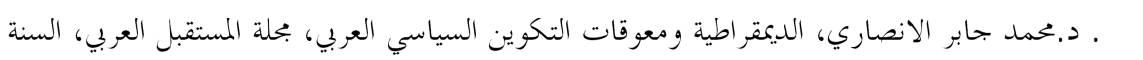
11، العدد "r.r. عَ". د.عبدالعليم، مصدر سابق، ص 1 -9.

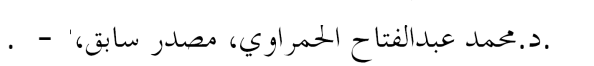
7س. ان من الصعب فهم الحد الفاصل بين البختمع المدني والبختمع السياسي من دون فهم طبيعة السلطة

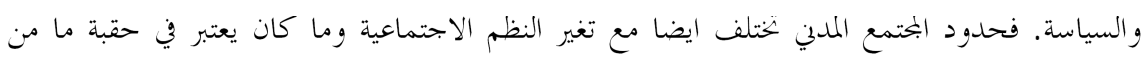

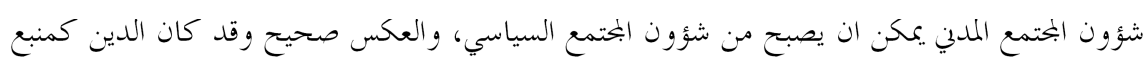

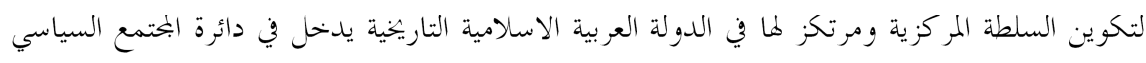

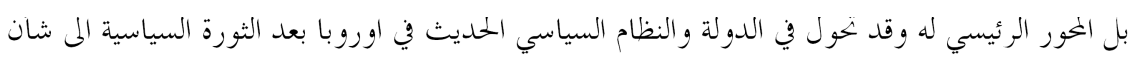
من شؤون البحتمع المدلي، وفرض عليه ذلك. IV

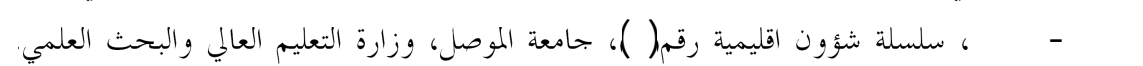

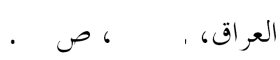

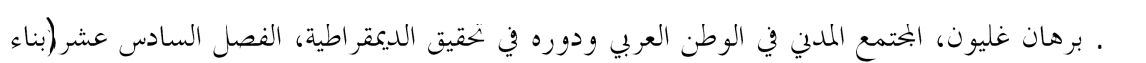

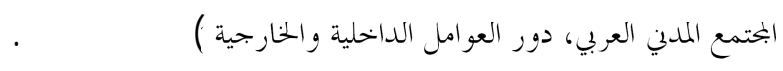


وس. و لا يعني الشان الخاص هنا الشان الفردي. فالدن لين شانا خاصا، ولكنه شان عام من حيث انه

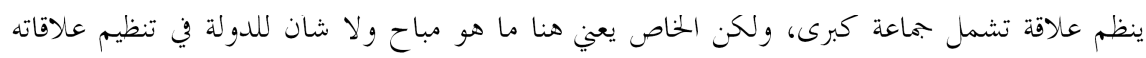

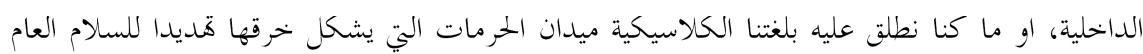
وبحاوزا من قبل السلطة المركزية لصلاحياتا.

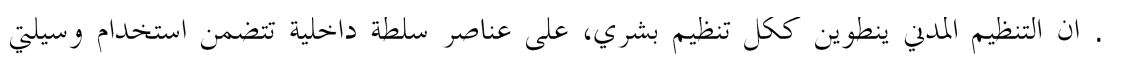

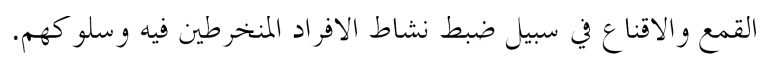

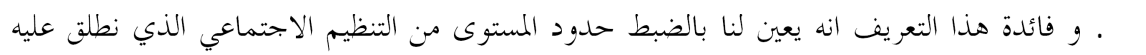

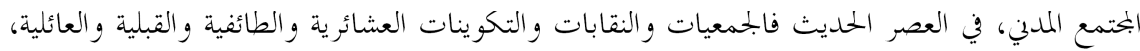

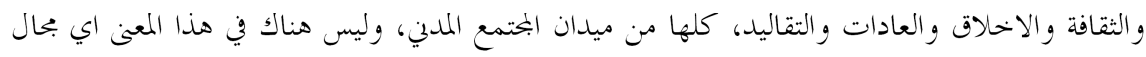

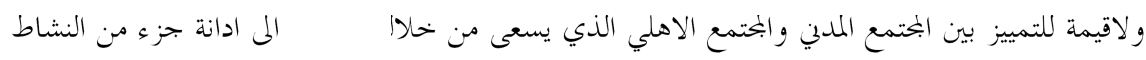

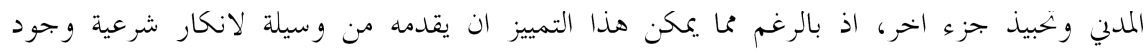

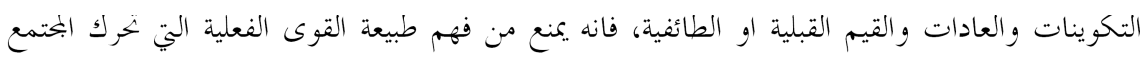

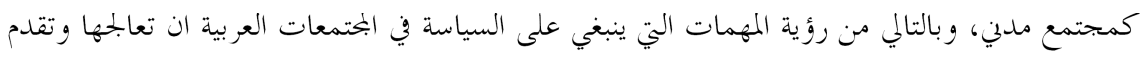

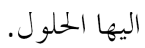

$$
\text { rع بع برهان غليون، البختمع المدني في الوطن العربي، مصدر سابق. }
$$

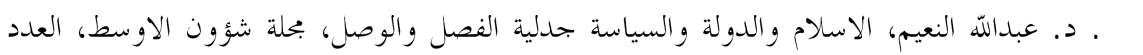

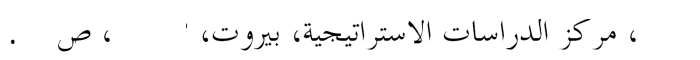

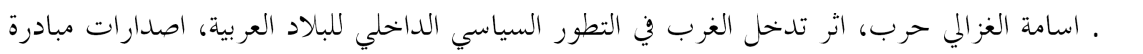
الاصلاح العربي، مصر، V. V. T.

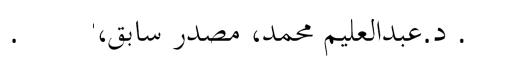

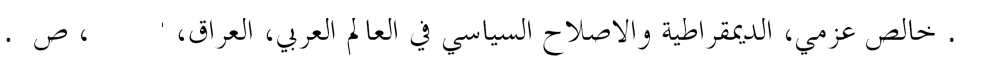
VV

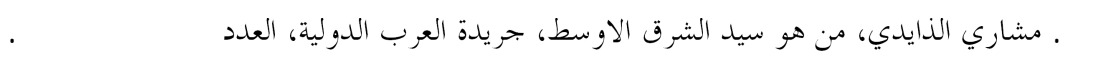

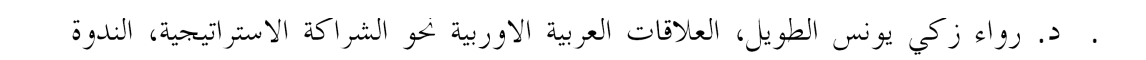

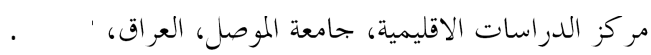


د. دواء زكي الطويل[ج]

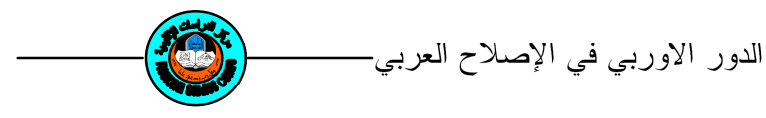

0. خالد غزال، موقع العالم العربي في العولمة، بحلة شؤون الاوسط، العدد عَا، مركز الدراسات

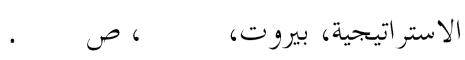

